\title{
Article \\ HIF-Dependent CKB Expression Promotes Breast Cancer Metastasis, Whereas Cyclocreatine Therapy Impairs Cellular Invasion and Improves Chemotherapy Efficacy
}

\author{
Raisa I. Krutilina ${ }^{1,+}$, Hilaire Playa ${ }^{1,+}$, Danielle L. Brooks ${ }^{1}$, Luciana P. Schwab ${ }^{1}$, Deanna N. Parke ${ }^{1}$, \\ Damilola Oluwalana ${ }^{1}(\mathbb{D})$, Douglas R. Layman ${ }^{2}$, Meiyun Fan ${ }^{1} \mathbb{D}$, Daniel L. Johnson ${ }^{3} \mathbb{D}$, Junming Yue ${ }^{1}$, \\ Heather Smallwood ${ }^{4}$ (D) and Tiffany N. Seagroves ${ }^{1, *}$
}

1 Center for Cancer Research, Department of Pathology and Laboratory Medicine, College of Medicine, The University of Tennessee Health Science Center, Cancer Research Building, 19 South Manassas Street, Memphis, TN 38163, USA; rkrutili@uthsc.edu (R.I.K.); hplaya@uthsc.edu (H.P.); danielle.laurene@gmail.com (D.L.B.); schwab.lp@gmail.com (L.P.S.); dparke2@uthsc.edu (D.N.P.); doluwala@uthsc.edu (D.O.); mFan2@uthsc.edu (M.F.); jyue@uthsc.edu (J.Y.)

2 School of Medicine, The University of Tennessee Health Science Center, Memphis, TN 38163, USA; drlayman11@gmail.com

3 Molecular Bioinformatics Core, Office of Research, The University of Tennessee Health Science Center, 71 South Manassas Street, Memphis, TN 38163, USA; djohn166@uthsc.edu

4 Department of Pediatrics, College of Medicine, The University of Tennessee Health Science Center, 71 South Manassas Street, Memphis, TN 38163, USA; hsmallwo@uthsc.edu

* Correspondence: tseagro1@uthsc.edu; Tel.: +1-901-448-5018

+ Co-first authors: Authors are listed in alphabetical order.

Citation: Krutilina, R.I.; Playa, H.; Brooks, D.L.; Schwab, L.P.; Parke, D.N.; Oluwalana, D.; Layman, D.R.; Fan, M.; Johnson, D.L.; Yue, J.; et al. HIF-Dependent CKB Expression Promotes Breast Cancer Metastasis, whereas Cyclocreatine Therapy Impairs Cellular Invasion and Improves Chemotherapy Efficacy. Cancers 2022, 14, 27. https:// doi.org/10.3390/cancers14010027

Academic Editor: Robert C. Bast, Jr.

Received: 20 November 2021

Accepted: 19 December 2021

Published: 22 December 2021

Publisher's Note: MDPI stays neutral with regard to jurisdictional claims in published maps and institutional affiliations.

Copyright: (c) 2021 by the authors. Licensee MDPI, Basel, Switzerland. This article is an open access article distributed under the terms and conditions of the Creative Commons Attribution (CC BY) license (https:// creativecommons.org/licenses/by/ $4.0 /)$.
Simple Summary: Targeting dysregulated cellular metabolism is a promising avenue to treat metastatic disease. The aim of our study was to identify genes downstream of the hypoxia-inducible factor (HIF)-1 transcription factor that are amenable to therapeutic intervention to treat metastatic breast cancer (MBC). We identified creatine kinase, brain isoform (CKB) as an HIF-dependent gene that strongly promotes invasion and metastasis in estrogen-receptor (ER)-negative breast cancer models. Deletion of $C k b$ also repressed glycolysis and mitochondrial respiration, leading to a reduction in intracellular ATP. Either the deletion of $C k b$ or inhibition of creatine kinase (CK) activity using the creatine analog cyclocreatine $(\mathrm{cCr}$ ) repressed cell invasion, the formation of invadopodia and lung metastasis. In addition, when paired with paclitaxel or doxorubicin, $\mathrm{cCr}$ enhanced growth inhibition in an additive or synergistic manner. $\mathrm{cCr}$ may be an effective anti-metastatic agent in ER-negative, HIF-1 $\alpha$-positive breast cancers, targeting both cellular metabolism and motility, particularly when paired with conventional cytotoxic agents.

\begin{abstract}
The oxygen-responsive hypoxia inducible factor (HIF)-1 promotes several steps of the metastatic cascade. A hypoxic gene signature is enriched in triple-negative breast cancers (TNBCs) and is correlated with poor patient survival. Inhibiting the HIF transcription factors with small molecules is challenging; therefore, we sought to identify genes downstream of HIF-1 that could be targeted to block invasion and metastasis. Creatine kinase brain isoform (CKB) was identified as a highly differentially expressed gene in a screen of HIF-1 wild type and knockout mammary tumor cells derived from a transgenic model of metastatic breast cancer. CKB is a cytosolic enzyme that reversibly catalyzes the phosphorylation of creatine, generating phosphocreatine (PCr) in the forward reaction, and regenerating ATP in the reverse reaction. Creatine kinase activity is inhibited by the creatine analog cyclocreatine ( $\mathrm{cCr}$ ). Loss- and gain-of-function genetic approaches were used in combination with $\mathrm{CCr}$ therapy to define the contribution of $\mathrm{CKB}$ expression or creatine kinase activity to cell proliferation, migration, invasion, and metastasis in ER-negative breast cancers. CKB was necessary for cell invasion in vitro and strongly promoted tumor growth and lung metastasis in vivo. Similarly, cyclocreatine therapy repressed cell migration, cell invasion, the formation of invadopodia and lung metastasis. Moreover, in common TNBC cell line models, the addition of cCr to conventional cytotoxic chemotherapy agents was either additive or synergistic to repress tumor cell growth.
\end{abstract}


Keywords: breast cancer; hypoxia; metabolism; creatine kinase; invasion; metastasis; chemotherapy

\section{Introduction}

A major clinical challenge in breast cancer is the treatment of metastatic disease. The overall survival of patients with metastatic breast cancer (MBC) remains dismal. Up to $30 \%$ of all patients will die within five years, and $\sim 6 \%$ of patients are initially diagnosed with stage IV disease [1]. Targeting dysregulated tumor cell metabolism is a promising avenue to address drug resistance and to prolong the survival of patients [2,3]. Several metabolic pathways that are altered in tumors, including glutamine metabolism, fatty acid metabolism and aerobic glycolysis, are linked to therapeutic resistance [3].

The hypoxic response and the oxygen-responsive hypoxia inducible factor (HIF) transcription factors play essential roles in mediating these pathways in tumors. HIF-1 and HIF-2 regulate genes that fine-tune cellular metabolism and that control cell proliferation, survival, or apoptosis [4,5]. HIF-1 is directly implicated in chemoresistance through the regulation of metabolic input [5-7]. Hypoxia in general, and the HIFs, specifically, promote breast cancer metastasis and therapeutic resistance [7-9]. Using a transgenic model of MBC (MMTV-PyMT), we have shown that HIF-1 $\alpha$ is essential for tumor growth and for the metastatic lung colonization of cells originating from the mammary gland [9].

Targeting the HIFs with small molecules remains challenging. Several HIF inhibitors have been described, but most do not discriminate between HIF-1 and HIF-2, and they indirectly impact HIF $\alpha$ stability / activity [10]. Furthermore, the deletion of either HIF $\alpha$ subunit is deleterious to normal development [11], suggesting potential toxicity. Finally, differential, or even competing roles, for HIF- $1 \alpha$ and HIF-2 $\alpha$ in tumorigenesis are reported [12].

To address these obstacles, we screened for genes downstream of HIF-1 that were differentially expressed after genetic knockout (KO) of HIF- $1 \alpha$ to identify targets potentially more amenable to therapeutic intervention. Genes implicated in cellular metabolism and/or invasion, or for which chemical inhibitors had been previously identified, were prioritized for biological validation. One gene meeting both criteria was creatine kinase, brain isoform (CKB).

$\mathrm{CKB}$ is a member of a family of four creatine kinase (CK) enzymes that reversibly transfer a high-energy phosphate group between ATP and creatine, generating phosphocreatine and ADP [13]. Phosphocreatine is an essential local energy reservoir which highly metabolic tissues exploit to rapidly re-generate ATP from ADP to maintain a high ratio of ATP / ADP and to prevent local acidification near cellular ATPases [14,15]. These functions are relevant to tumors, which rely on aerobic glycolysis to produce energy and exist in an acidic microenvironment [6]. All four CK isoforms (two cytosolic, two mitochondrial) and the creatine transporter (SLC6A8) are direct HIF-responsive genes [16]. Neither CKB nor the mitochondrial isoform CKMT1 are essential for development because single or compound knockout mice are viable [17]. CKB is over-expressed in several solid tumors including breast, colorectal, and ovarian [18-20]. In proteomic screens of prostate, lung, and HER2+ breast cancers, CKB was elevated [21-24].

Targeting creatine kinases is underdeveloped as an anticancer strategy targeting cellular metabolism. In the 1990s, several creatine analogs, including cyclocreatine (1carboxymethyl-2-iminoimidazolidine, $\mathrm{cCr}$ ), were shown to inhibit tumor growth with tolerable side effects [15]. Cyclocreatine has the most similar substrate kinetics to creatine, but unlike creatine, which is actively transported into cells by SLC6A8, cCr passively enters cells. cCr therapy was reported to repress rat mammary adenocarcinoma growth [25]; however, the impact on metastasis was not tested. Cyclocreatine also inhibits tumor cell motility in vitro [26]. In a colon cancer model, CKB was shown to mediate the metastatic potential of cancer cells by acting as a secreted kinase to produce phosphocreatine, which accumulated in the stroma and was then re-imported into tumor cells to promote CKdependent survival to facilitate liver colonization [27]. In pancreatic adenocarcinoma, 
$\mathrm{CKB}$ was identified as a mechanosensitive transcriptional target of Yes-associated protein 1 (YAP). Stiff substrates increased CKB levels and ATP production to promote collective cell invasion and chemotaxis [28]. These pre-clinical studies build upon prior in vitro observations which suggest that $\mathrm{CKB}$ localizes in a spatially restricted manner in migrating cells to supply local ATP necessary for actin reorganization $[29,30]$.

We tested whether the creatine phosphagen arm of metabolism may be a key player downstream of the HIFs to promote breast cancer metastasis to the lung, a predominant site of metastasis in women with triple-negative breast cancer (TNBC) [31]. Using in vitro and in vivo approaches, including the genetic modification of $\mathrm{CKB}$ compared with $\mathrm{cCr}$ treatment, we conclude that breast tumor-cell-intrinsic expression of CKB is required to mediate cellular metabolism and to promote metastasis in ER-negative breast cancer models. Moreover, the addition of $\mathrm{cCr}$ to conventional cytotoxic agents represses tumor growth in an additive or synergistic manner.

\section{Materials and Methods}

\subsection{Chemicals}

Cyclocreatine (cCr) and doxorubicin (DOX) were purchased from either Sigma-Aldrich (St. Louis, MO, USA, \#377627, or \#D1515; 98\% purity) or Cayman Chemical Company (cat\# 20649, >95\% purity, Ann Arbor, MI, USA), and paclitaxel (>99.5\% purity; Taxol) was purchased from LC Laboratories (cat.\# P-9600, Woburn, MA, USA). For in vitro studies, cCr stock was freshly diluted to $50 \mathrm{mM}$ in complete growth medium immediately before use. Paclitaxel and doxorubicin were prepared in DMSO as $20 \mathrm{mM}$ and $5 \mathrm{mM}$ stocks, respectively, and stored at $-20{ }^{\circ} \mathrm{C}$; thawed stocks were serially diluted in DMSO to prepare working stocks for in vitro assays. For use in vivo, cCr was dissolved to $\sim 1.92 \mathrm{mg} / \mathrm{mL}$ into sterile $0.9 \%$ saline using gentle heat, sterile-filtered, and at $-20{ }^{\circ} \mathrm{C}$. Prior to treatment, the frozen aliquot was heated to $\sim 50{ }^{\circ} \mathrm{C}$, transferred to a sterile glass evacuated vial, and stored protected from light in a thermos heated to $37^{\circ} \mathrm{C}$. $\mathrm{cCr}$ was immediately injected into mice (IP) at a final dose of $1.0 \mathrm{~g} / \mathrm{kg} /$ day.

\subsection{PyMT Mammary Tumor Epithelial Cells (MTECs)}

HIF-1 WT and KO MTECs were maintained as in [9]. All cells were cultured at normoxia (ambient air) or exposed to hypoxia $\left(0.5 \% \mathrm{O}_{2}\right)$ in a Sanyo multi-gas incubator (acutely, $\leq 6 \mathrm{~h}$, or chronically, 16-24 h).

\subsection{RNA Extraction and Gene Expression Microarray Analysis}

HIF-1 WT and KO PyMT cells were grown in DMEM/F12 medium ( $n=6$ wells/genotype) supplemented with 2\% FBS and $15 \mathrm{mM}$ HEPES. At $~ 80 \%$ confluence, plates were left at normoxia or transferred to hypoxia $\left(0.5 \% \mathrm{O}_{2}\right)$ for $6 \mathrm{~h}$, when HIF-1 transcriptional activity peaked [9]. At harvest, individual wells were washed with cold PBS, scraped, and cells were pelleted and flash-frozen. Total RNA was prepared from partially thawed cell pellets using RNABee reagent (Tel-Test, Friendswood, TX, USA). RNA specimens were compared for integrity using the Agilent bio-analyzer assay, and for each genotype/condition, 3 of the 6 samples with the highest RNA integrity number (RIN) value were selected for microarray analysis. Independent replicate total RNA samples were hybridized to the MouseRef6v1.1 Expression BeadChip Kit (Illumina, San Diego, CA, USA) at the UTHSC Molecular Resource Center of Excellence (MRC). Raw data were transformed to the $\log _{2}$-scale, and normalized log-scale intensity values were analyzed for differential expression using Expander. All genes with a mean fold differential $\geq 2.0(p<0.05)$ are included in gene lists (Supplementary Tables S1-S3), and can be assessed in GEO (GSE183694). Supplementary Tables S1-S3 include differentially expressed gene lists from the following comparisons, respectively: Table S1: HIF-1 WT at normoxia vs. HIF-1 WT at hypoxia, Table S2: HIF-1 WT vs. HIF-1 KO, at normoxia and Table S3: HIF-1 WT vs. HIF-1 KO, at hypoxia. 


\subsection{Real-Time Quantitative PCR ( $q P C R)$}

Total RNA was converted to cDNA using the High-Capacity cDNA Reverse Transcription Kit (Applied Biosystems, Waltham, MA, USA). qPCR was performed on the Roche LC480 instrument using default cycling parameters. Crossing point $(\mathrm{Cp})$ values were normalized based on the expression of the integrator complex subunit 3 (Ints3) for mouse genes, or cyclophilin A (PPIA) for human genes. To compensate for any changes in epithelial content in total RNA extracted from whole tumors, because only the tumor epithelium is deleted for Hif1a, Ints3-normalized Cp values were also normalized to Krt18 (K18). Primer and probe sets were designed by the Universal Probe Library (UPL) assay design center; all primers are listed in Supplementary Table S4.

\subsection{Immunofluorescence of Cultured Cells}

Cells were cultured to sub-confluence in multi-well chamber slides (ibidi, Gräfelfing, Germany). At harvest, cells were washed with cold PBS and fixed with $4 \%$ paraformaldehyde/PBS before permeabilization with $0.1 \%$ Triton-X, washing in PBS + Tween-20 (PBST), and blocking with buffer containing both BSA and normal serum. Primary antibodies to $\mathrm{CKB}$, cortactin, or alpha-tubulin were incubated at $4{ }^{\circ} \mathrm{C}$ overnight in blocking buffer. Cortactin and tubulin were detected with anti-IgG secondary antibodies for $1 \mathrm{~h}$ at RT (either AlexaFlour-488, or -594, Life Technologies, Waltham, MA, USA). Tertiary amplification was used to detect $\mathrm{CKB}$; after primary antibody, cells were incubated with donkey anti-rabbitbiotin-X-IgG secondary antibody (cat. \#A16027, Life Technologies, Waltham, MA, USA, $1 ; 400)$, washed, and then incubated with Alexa-Fluor-594-conjugated streptavidin. Prior to mounting, cells were counterstained with DAPI, washed, and then ibidi mounting medium was added. A list of all antibody reagents is included in Supplementary Table S5. Slide images were captured on a Nikon inverted ECLIPSE Ti2 microscope using NIS-Elements software and the enhanced intensity projection module using compiled images from multiple z-stacks.

\subsection{Protein Extraction and Western Blotting}

Whole cell extracts (WCEs) and high-salt-enriched WCE (HS-WCE) fractions were prepared, and Western blotting was performed as in [9]. To detect HIF-1 $\alpha$, HS-WCE (5 $\mu \mathrm{g})$ was resolved on 3-8\% Tris-Acetate gels. For CKB, WCEs (20-40 $\mu$ input) were resolved on either $4-12 \%$ Tris-Bis or 10\% Tris-Bis BOLT gels (Life Technologies) and transferred onto a PVDF Fluorescent (PVDF-FL) membrane (Millipore, Burlington, MA, USA). To confirm equivalent loading, membranes were immunostained with antibodies, as described in the figure legends, or were stained prior to blotting with Ponceau S (Sigma, St. Louis, MO, USA) and scanned. Ponceau S-stained membranes were de-stained prior to blocking with either 5\% non-fat dry milk (NFDM)/TBST for enhanced chemiluminescence (ECL) or with Odyssey blocking buffer (LiCor Biosciences, Lincoln, NE, USA) for near-infrared (NIR) detection. Membranes were probed with primary antibodies followed by extensive washing and incubation with anti-rabbit whole IgG secondary antibodies conjugated to either HRP (Jackson Immunologicals, West Grove, PA, USA) or to NIR fluorophores (LiCor Biosciences, Lincoln, NE, USA). Antibody complexes were detected by ECL and membranes were exposed to film, or membranes were directly imaged using the LiCor Odyssey or Azure Sapphire NIR imaging systems. In some cases, membranes were stripped with ReBlot Plus Mild (Millipore, Burlington, MA, USA), then re-blocked and incubated with antibodies to $\beta$-tubulin or PARP. Alternatively, .tiff images of Ponceau-S-stained membranes were analyzed by ImageStudio densitometry analysis (LiCor Biosystems, Lincoln, NE, USA) to agnostically quantitate whole lane signals.

\subsection{Creatine Kinase Enzymatic Activity Assay}

Protein extracts were analyzed by a CK assay (cat.\#: C712-39, Pointe Scientific, Canton, MI, USA) and activity was normalized to total protein content. 


\subsection{Patient Database Mining}

Datasets were analyzed using The Cancer Genome Atlas (TCGA) database [32] and Kaplan-Meier (KM) Plotter [33]. The level of CKB mRNA expression in breast tumor subtypes was derived from the TCGA data portal (http: / / cancergenome.nih.gov /, accessed on 4 October 2016). Level three normalized data derived from Illumina RNASeqv2 data compared mRNA expression, and samples were stratified by tumor subtype based on the PAM50 method. Plots with $p$-values $\leq 0.05$ (ANOVA with Bonferroni correction) were considered significant. For regression-free survival (RFS) analysis, KMPlotter data for breast cancer patients were stratified by CKB (200884_at) mRNA levels (top tertile vs. lower tertiles) or overall survival (OS) was stratified by CKB protein levels (P12277; using the optimal threshold). KMPlotter was last accessed 13 December 2021.

\subsection{Promoter Analysis and Chromatin Immunoprecipitation (ChIP) Assays}

The mouse $(C k b)$ and human $(C K B)$ proximal promoters $(-2000$ to $+500 \mathrm{bp})$ were scanned for putative functional hypoxic response elements (HREs) using the Transcription Factor Matrix (TFM) Explorer algorithm and weight matrices available from JASPER and TRANSFAC. PyMT HIF-1 WT and KO cells and MCF7 empty vector (pLKO.1-puro or EV) or shHIF1A transduced cells described in [34] were cultured at normoxia or $0.5 \% \mathrm{O}_{2}$ (hypoxia) for 6-24 h and fixed with 1\% formaldehyde for $12 \mathrm{~min}$. Positive controls included a previously validated functional HRE in the Vegf promoter for PyMT cells [35] and a previously validated functional HRE identified in the EPO promoter [36] for MCF-7 cells. Primers were designed to putative independent HRE sites, as well as to non-HRE sequences in the promoter regions (Supplementary Table S6). DNA was sheared to $500 \mathrm{bp}$ and ChIP was performed using antibodies against HIF-1 $\alpha$ or anti-rabbit IgG control, and raw data were analyzed as in [37].

\subsection{Generation of PyMT Ckb Knockdown Cells}

PyMT HIF-1 WT cells were used to create $C k b$ stable shRNA knockdown (KD) via lentiviral transduction. First, a $C k b$ shRNA library containing 3 independent $C k b$ targeting sequences individually cloned into the pLKO.1-puro vector was purchased from Open Biosystems (clone IDs: TRCN0000024659, "sh59", TRCN0000026460, "sh60" and TRCN0000024661, "sh61"; shRNA targeting sequences are listed in Supplementary Table S7). Cells $\left(1 \times 10^{6}\right)$ were transfected with each shRNA plasmid $(4 \mu \mathrm{g})$ by nucleofection with kit $\mathrm{T}$ and program setting 24 (Nucleofector, Lonza, Basel, Switzerland) to screen for deletion efficiency. Two shRNAs (sh59 and sh61) were chosen to produce lentivirus particles in addition to the pLKO.1-empty (empty vector, EV). All lentiviruses were produced by Dr. Junming Yue of the UTHSC Viral Vector Core. HIF-1 WT cells were also transduced with empty pLKO.1-puro vector ("empty vector", EV). PyMT cells were transduced with lentivirus particles $(\mathrm{MOI}=50)$. Puromycin $(2 \mu \mathrm{g} / \mathrm{mL})$ was added $72 \mathrm{~h}$ later and a "pool" of surviving clones (representing several hundred colonies) was established for each shRNA. Stably transduced lines were maintained in growth media plus $1 \mu \mathrm{g} / \mathrm{mL}$ puromycin; antibiotic selection was removed from cells at least 4 days before biological assays or treatments with cCr. Two constructs, sh59 and sh61, produced $>70 \%$ knockdown, with sh61 showing the highest efficiency of deletion (Supplementary Figure S2A,B).

\subsection{PyMT Cell Proliferation Assay by WST-1}

Cells were grown at normoxia or hypoxia in medium buffered with $15 \mathrm{mM}$ HEPES. The day before enumeration, 20,000 cells were plated into 96-well plates in normal growth medium ( $n=3$ wells/genotype/oxygen tension/time point). The medium was changed $24 \mathrm{~h}$ post-plating, when the first cell harvest was collected $(\mathrm{t}=0 \mathrm{~h}$ time point), but media were not replenished for the duration of the experiment. Background absorbance was subtracted, and raw data were normalized to the EV controls (\% maximal proliferation vs. $\mathrm{EV})$. To generate a $\mathrm{CC}$ dose-response curve, at $24 \mathrm{~h}$ post-seeding, growth media without drug or with media containing increasing doses of $\mathrm{cCr}$ (from $2 \mathrm{mM}$ to $50 \mathrm{mM}$ ) were replaced. 
Cells were incubated for $96 \mathrm{~h}$ and then analyzed with the WST-1 assay (Chemicon, cat.\#2210, Burlington, MA, USA). Growth inhibition was measured as the change in absorbance over time, normalized to the vehicle control for each cell line (set to $100 \%$ ).

\subsection{Wound Healing Assays}

PyMT EV, HIF-1 KO, and Ckb KD cells were plated in 12-well plates in growth medium (30,000 cells / well; $n=3$ wells per genotype) and grown to $100 \%$ confluence. A scratch with a $1 \mathrm{~mL}$ tip in a vertical and horizontal direction was applied to each well. Cells were washed to remove the detached cells and fresh growth medium was added $(t=0 \mathrm{~h})$. Images were captured a $100 \times$ magnification at $0,8,24,32,48,56$ and $72 \mathrm{~h}$, and analyzed for open wound area/total area using ImageJ. Additional wound healing assays were performed using the IncuCyte S3 live-cell imaging system. PyMT EV cells were pre-incubated for $24 \mathrm{~h}$ with $25 \mathrm{mM}$ cCr in growth media supplemented with $2 \%$ FBS. Cells were plated into 96-well format Image Lock microplates (Sartorius, Göttingen, Germany) at 40,000/cells /well ( $n=8$ technical replicates/condition), such that cells would be $100 \%$ confluent approximately $24 \mathrm{~h}$ later. The WoundMaker tool created a uniform 700-800 $\mu \mathrm{M}$ scratch/well, the wounds were washed and growth medium containing either vehicle or $25 \mathrm{mM} \mathrm{cCr}$ was applied. Wounded EV cells that were not pre-treated with cCr were exposed to vehicle or to $\mathrm{cCr}$ (25 mM). Raw data were analyzed using the total wound area algorithm and exported into Prism 9.0.

\subsection{Human Breast Cancer Cell Lines, Mycoplasma Testing and Cell Line Authentication}

All cells were obtained from the Fan laboratory at UTHSC via the American Type Culture Collection (ATCC) and grown in base media (DMEM-Hi: MDA-MB-231 and MDAMB-453 cells, DMEM/F-12: MDA-MB-468 cells or RPMI: BT549 cells) supplemented with 10\% FBS (cat.\# FB-01, Omega Scientific, Tarzana, CA, USA). All cells were authenticated at the University of Arizona Genetics Core. Cells were routinely screened for mycoplasma using the Lonza MycoAlert kit.

\subsection{Transient Ectopic Expression of CKB in $M D A-M B-231$ Cells}

MDA-MB-231-NR (NucLight red) cells (generously provided by Sartorius; RRID:CVCL_DF48) were transfected with FuGene HD reagent (Promega, Madison, WI, USA) with $3 \mu \mathrm{g}$ of either pCMV-6-Entry vector (OriGene, cat\# PS100001, Rockville, MD, USA) or pCMV-6Entry expressing the CKB TrueORF (cat\#RC203669); cells were selected with neomycin $(2 \mathrm{mg} / \mathrm{mL})$.

\subsection{Invasion Assays}

PyMT EV, HIF-1 KO and Ckb KD cells were first gradually weaned from growth medium supplemented with $2 \%$ FBS to $0.5 \%$ FBS, as in [9]. Cells were then cultured for $18 \mathrm{~h}$ in serum-free DMEM/F-12 medium. The next day, 25,000 cells were plated onto control inserts or Matrigel-coated transwell inserts (BD Biosciences, San Jose, CA) and attracted to wells containing DMEM/F12 medium supplemented with 5\% FBS ( $n=3$ wells/genotype). The mean cell invasion index corrected for random migration was calculated at $48 \mathrm{~h}$ postseeding. To determine whether re-expression of CKB in HIF-1 KO PyMT cells would rescue invasion, vector control or HIF-1, $\mathrm{KO}$ cells stably transfected to express mCKB were gradually weaned to $0.5 \%$ FBS and then plated at a density of 40,000 cells into transwell inserts (with and without coating with Matrigel) and attracted to 5\% FBS for $48 \mathrm{~h}$. MDA-MB231 transiently transfected cells (empty vector or $+\mathrm{mCKB}$ ) were serum-starved overnight before plating onto transwell inserts and then attracted to medium supplemented with $10 \%$ FBS for $24 \mathrm{~h}$. For studies comparing normoxia to hypoxia, changes in PyMT cell invasion are expressed as the fold change relative to the invasion index observed for HIF-1 WT cells cultured at normoxia (fold change $=1.0$ ). Otherwise, all other data are expressed as the percentage of invading cells (invading cells/total cells plated). 


\subsection{Intracellular ATP Levels}

Intracellular ATP levels were compared using the high-sensitivity ATP Bioluminescence Assay HS II kit (cat. \#11699709001, Sigma, St. Louis, MO, USA). PyMT cells were grown to $80 \%$ confluence prior to incubation at normoxia or hypoxia for $24 \mathrm{~h}(n=3$ per genotype/condition). Cells were harvested and lysed using the kit lysis reagent supplemented with cOmplete EDTA-free tablets (cat. \# 4693132001, Sigma, St. Louis, MO, USA). Luciferase reagent was added $1 \mathrm{~s}$ prior to a $10 \mathrm{~s}$ integrated reading on a single-tube luminometer. A blank (reagent only) reading was obtained and subtracted from all sample readings. An ATP standard curve was generated to plot bioluminescence versus molarity on a log-log scale and used to calculate intracellular ATP concentrations. DNA concentrations for each individual sample were measured using a Qubit ${ }^{\circledR}$ fluorometer (Life Technologies, Waltham, MA, USA), and ATP concentrations were normalized to total DNA.

\subsection{Seahorse Bioanalyzer Assays}

PyMT cells were seeded into Seahorse XFe-96 sensor plates (Agilent Technologies, Santa Clara, CA, USA) to produce near-confluence within $18 \mathrm{~h}$. The next day, the plate was transferred to the Department of Pediatrics Bioenergetics Core for profiling on the XFe96 Extracellular Flux Analyzer. Cells were switched to an XF base medium supplemented with L-glutamine (2 mM) for the XF Cell Glyco Stress test or with glucose (10 mM), L-glutamine $(2 \mathrm{mM})$, and sodium pyruvate $(1 \mathrm{mM})$ for the XF Cell Mito Stress test. Cells were equilibrated for $1 \mathrm{~h}$ prior to analysis of the extracellular acidification rate (ECAR) or the oxygen consumption rate (OCR). After each run, the cell number was quantified using CyQUANT dye (Thermo Scientific, Waltham, MA, USA). Metabolic rates were calculated using the Seahorse XF report generator, and data were imported into Prism 9.0 for analysis.

\subsection{Chemotaxis Assays}

Chemotaxis assays were performed in the IncuCyte S3 imager, as recommended by Sartorius; MDA-MB-231-NR cells transiently transfected (48 h) with empty vector (EV, pCMV-6-Entry) or expressing mCKB $(+\mathrm{mCKB})$ were seeded at a density of 1000 cells / per well of a 96-well ClearView chemotaxis plate (cat. \#4582, Sartorius) ( $n=4-6$ technical replicates/cell line), which allows cell tracking in real time through optically clear membrane inserts. Cells were exposed to a reservoir containing DMEM $+10 \%$ FBS as the chemoattractant. The chemotaxis analysis software tool was used to quantify cell migration. Raw data were normalized for initial plating density prior to export to Prism 9.0.

\subsection{Cell Cycle Analysis}

PyMT EV or sh61 KD cells were plated into 6-well dishes, and when sub-confluent, they were treated with vehicle control or with $25 \mathrm{mM} \mathrm{cCr}$ for either $24 \mathrm{~h}$ (added $24 \mathrm{~h}$ prior to experiment endpoint) or $48 \mathrm{~h}$. Harvested cell pellets were washed twice with cold PBS and re-suspended in $5 \mathrm{~mL}$ ice-cold $70 \%$ ethanol prior to storage at $4{ }^{\circ} \mathrm{C}$. Prior to cytometry, samples were washed with PBS and treated with RNaseI. Setting aside an unstained sample as the gating control, propidium iodide $[50 \mu \mathrm{g} / \mathrm{mL}]$ was added and incubated at $37^{\circ} \mathrm{C}$ for $15 \mathrm{~min}$ prior to analysis on a BioRad ZE5 flow cytometer at the UTHSC Flow Cytometry and Cell Sorting (FCCS) Core. Raw data were exported to ModFit for analysis $(n=3$ replicates/genotype/time point, and at least duplicate biological replicates per time point).

\subsection{PyMT Primary Tumor Generation}

PyMT EV, HIF-1 KO, sh59 Ckb KD and sh61 Ckb KD MTECs were dissociated into single cells, diluted 1:1 in growth factor reduced Matrigel (BD Biosciences, Franklin Lakes, NJ, USA):HBSS, and injected into the cleared inguinal mammary fat pads of recipients (50,000 cells $/ 10 \mu \mathrm{L})$. Tumor volume was measured with digital calipers as in [9]. Primary tumors of all genotypes were resected (at $\sim 500 \mathrm{~mm}^{3}$ ) at similar volumes in a survival 
surgery under anesthesia, and mice were allowed to survive until moribund due to lung metastasis.

\subsection{Tissue Immunohistochemistry and Quantification}

Harvested tumors were bisected with a razor and fixed for 8-24 h in 10\% neutralbuffered formalin (NBF), followed by paraffin embedding and sectioning. Antigen retrieval was performed in $1 \times$ citrate buffer ( $\mathrm{pH}$ 6.0) in a pressure cooker. Endogenous peroxidase was blocked by $3 \% \mathrm{H}_{2} \mathrm{O}_{2} / \mathrm{MeOH}$ for $20 \mathrm{~min}$, followed by washing in water then PBS. All slides were blocked in 10\% normal serum/PBST at least $1 \mathrm{~h}$ at RT before incubation of the primary antibody overnight in humid chambers at $4{ }^{\circ} \mathrm{C}$. Slides were washed then stained with the ABC Elite anti-rabbit kit (cat. \# PK-6100, Vector Labs, Burlingame, CA, USA) and developed using DAB Impact (cat. \#SK-4105, Vector Labs) and counterstained in hematoxylin (cat.\# H3401, Vector Labs). Whole slides were digitally scanned using a 3DHISTECH PANORAMIC slide digitizer (3D Histech, Ltd. software, Budapest, Hungary). Staining intensity was analyzed by pixel counts using built-in densitometry algorithms for nuclear or cytoplasmic localization. Following masking to exclude necrosis, whole tumors were analyzed after the general background was set using an adjacent tissue section developed without primary antibody. Antibody reagents are listed in Supplementary Table S5.

\subsection{Tail Vein Assays in PyMT Mice}

PyMT EV, sh59 and sh61 Ckb KD cells $\left(1 \times 10^{6}\right)$ were injected via the tail vein, mice were sacrificed after 21 days, and lungs were inflated with formalin. Lung sections representing every $100 \mu \mathrm{m}$ were stained with $\mathrm{H} \& \mathrm{E}$ and metastasis was scored [9]. To test cCr efficacy, PyMT EV cells were injected and allowed to seed the lungs for $24 \mathrm{~h}$. The cCr dosing regimen was based on [25]. Mice were treated with vehicle (0.9\% saline, daily, IP) or $\mathrm{cCr}$ $(1 \mathrm{~g} / \mathrm{kg}$, daily, IP) beginning 1 day post-injection. In an additional cohort, treatment with cCr was delayed until 7 days post-injection (after micro-metastases had formed), and then on day 21 post-injection, all mice were euthanized.

\subsection{Invadopodia Assays Using Human TNBC Cells}

Glass coverslips were coated with OregonGreen-gelatin (cat. \#G13186, ThermoFisher) as in [38]. Cells (BT549, 12,000/well or MDA-MB-231, 15,000/well) were seeded onto coverslips in growth media containing a reversible MMP inhibitor, batimistat $(10 \mu \mathrm{M}$; cat. \# SML0041, Sigma, St. Louis, MO, USA) and incubated overnight. The next day, the media were replaced with fresh growth media (vehicle) or $\mathrm{cCr}(25 \mathrm{mM})$ was added. Subsequently, 12-well plates containing seeded coverslips were placed into the IncuCyte S3 imager and simultaneously imaged for green fluorescence and phase contrast ( $n=16 \mathrm{im}$ ages/coverslip/time point). The green fluorescent area was normalized to seeding density per image and graphed as a ratio of change over time in Prism 9.0. At the end of the imaging, optimized per cell line, coverslips were fixed and immunostained prior to mounting directly onto glass slides using ProLong Gold Antifade media (cat.\# P36930, ThermoFisher, Waltham, MA, USA). Coverslips were imaged on a Nikon ECLIPSE Ti2 microscope, as described elsewhere.

\subsection{Growth Inhibition during Chemotherapy Treatment}

One day before measuring growth, cells were seeded into 96-well flat-bottomed plates such that assay imaging would begin the next day at $\sim 20 \%$ confluence (MDAMB-468: 8000 cells/well; MDA-MB-453: 12,000 cells/well; MDA-MB-231 or BT549 cells: 5000 cells/well). At $t=-1 \mathrm{~h}$, growth media from seeded cells were removed and each dilution of chemotherapy drug, or the vehicle control, was spiked into fresh media containing either IncuCyte Nuclight Rapid Red reagent (cat.\# 4717, Sartorius, Göttingen, Germany) or Miami Green (cat.\# EMI001, Kerafast, Boston, MA, USA) to enumerate cell nuclei. Plates were imaged in the IncuCyte S3 instrument. The growth inhibition percentage was calculated relative to vehicle controls, by the measurement of red or green fluorescent units 
localized to the nucleus after applying the IncuCyte masking algorithm to enumerate cell count. Data were exported to Prism 9.0 and normalized to initial seeding density. Drug synergism was calculated using the isobole method [39], wherein a combination index of $>1.0$ indicated antagonism, an index of $\sim 1.0$ was additive and an index of $<1.0$ suggested synergism.

\subsection{Statistical Analysis}

Unless otherwise stated, all data were entered into Prism 9.0 (Graph Pad, San Diego, CA, USA) and analyzed using one-way or two-way ANOVA, followed by multiple pairwise comparison tests ( $t$-tests). If the standard deviation was not similar between two groups, Welch's correction was applied. Graphs show the mean \pm SEM and significance was determined with a 95\% confidence level; $p$-values on all graphs are indicated by asterisks: ${ }^{*} p<0.05,{ }^{* *} p<0.01,{ }^{* * *} p<0.001,{ }^{* * * *} p<0.0001$.

\section{Results}

\subsection{Ckb Is a HIF-1 $\alpha$ Dependent Target in Breast Cancer}

Tumor-cell-intrinsic HIF- $1 \alpha$ is required for mammary tumor growth and lung metastasis in a MMTV-PyMT mouse model [9]. To identify genes downstream of HIF-1 that mediate metastasis and may be more amenable to therapeutic intervention, we performed microarray profiling using HIF-1 WT and KO PyMT cells cultured at normoxia or $6 \mathrm{~h}$ of hypoxia. Several hundred differentially expressed genes were identified for the following comparisons: (1) HIF-1 WT normoxia vs. HIF-1 WT hypoxia; (2) HIF-1 WT normoxia vs. HIF-1 KO normoxia; (3) HIF-1 WT hypoxia vs. HIF-1 KO hypoxia (refer to Supplementary Tables S1-S3, respectively). Several genes down-regulated in HIF-1 KO cells, including Egln3 (Phd3), aldolase C (Aldoc), and Pdk1, are known HIF-1 $\alpha$ targets.

The enzyme creatine kinase brain isoform (CKB) was one of the top HIF-dependent differentially expressed genes, at normoxia and hypoxia. Ckb was down-regulated in normoxic HIF-1 KO cells by 13.4-fold ( $p=0.0093$ ) (Table S2). Following acute hypoxia exposure, $C k b$ expression in HIF-1 WT cells was 16.42-fold higher than in KO cells $(p=0.0002)$ (Table S3). However, $\mathrm{Ckb}$ was not differentially expressed in HIF-1 WT cells between normoxic and hypoxic exposure (Table S1). Based on CKB's well-described role in regulating energy metabolism, and prior studies using creatine analogs to inhibit the creatine kinase pathway, including cyclocreatine (cCr) [40], we sought to determine whether CKB plays a key role in mediating breast cancer metastasis. Microarray profiling was performed using HIF-1 WT and KO cells derived from the PyMT model, because $100 \%$ of mice will develop lung metastasis on the FVB/Nj strain [41]. Likewise, primary tumors regenerated from HIF-1 WT PyMT tumor cells develop lung metastasis with $100 \%$ penetrance [9].

To validate $C k b$ mRNA expression changes, independent sets of PyMT HIF-1 WT and $\mathrm{KO}$ cells were exposed to normoxia or hypoxia and qPCR was performed. There were no significant changes in Ckb mRNA levels in HIF-1 WT cells comparing normoxia (0 h of hypoxia) with $6 \mathrm{~h}$ or $24 \mathrm{~h}$ of hypoxia exposure (Figure 1A). In contrast, the largest decrease in $C k b$ mRNA levels in HIF-1 KO cells was observed at normoxia ( $0 \mathrm{~h}$ of hypoxia), with a mean decrease of 7.44-fold among three replicate experiments. However, in response to hypoxia, the difference in Ckb expression levels between HIF-1 WT normoxic and KO hypoxic cells was smaller in magnitude, $\sim 1.7$-fold ( $6 \mathrm{~h}$ of hypoxia) or 2.0-fold ( $24 \mathrm{~h}$ of hypoxia) (Figure 1A). It is possible that during hypoxia, HIF-2 $\alpha$ is compensating for the loss of HIF-1 function by up-regulating $C k b$ transcription, as has been observed in colon cells [16]. We next investigated whether CKB is a direct HIF-1 transcriptional target in PyMT cells and in MCF-7 cells, which are known to express CKB in an estrogen-responsive manner [42]. Two hypoxia-response elements (HREs) were identified in the murine $C k b$ or human $C K B$ promoters (Supplementary Figure S1A). Chromatin immunoprecipitation (ChIP) assays were performed using PyMT HIF-1 WT and KO cells or MCF-7 cells modified to express only the pLKO.1-puro (empty vector, EV) or shRNA to HIF1A [43]. HIF-1 $\alpha$ was recruited to the -1326 and -1835 sites in PyMT WT cells (Supplementary Figure S1B), 
with enrichments in HRE site occupancy of 11.5-fold or 4.6-fold, respectively. There was a 1.8-fold enrichment of HIF- $1 \alpha$ at the -258 HRE site in MCF-7 EV cells relative to shHIF1A cells. However, no enrichment at the -935 site was observed (Supplementary Figure S1C). Therefore, HIF-1 directly regulates CKB expression in breast cancer cells, as reported for the colon [16]. Knockdown (KD) of HIF1A in MCF-7 cells significantly down-regulated CKB mRNA levels (Supplementary Figure S1D).

$\mathrm{CKB}$ protein levels were also compared by Western blotting. Exposure of HIF-1 WT PyMT cells to hypoxia for $24 \mathrm{~h}$ did not induce CKB protein above normoxic $(0 \mathrm{~h})$ levels (Figure 1B); in fact, protein levels slightly decreased after $24 \mathrm{~h}$ of hypoxia. Immunofluorescence also confirmed reduced CKB expression in HIF-1 KO PyMT cells (Figure 1C). CKB was localized to the cytoplasm in a perinuclear pattern, as well as to the nucleus. CKB association with the nuclear matrix has been reported in colon cancer cells [44]. CKB levels were then compared in PyMT HIF-1 WT and HIF-1 KO end-stage tumors [9]. A reduction in $C k b$ mRNA, normalized for epithelial content using keratin 18 (Krt18), (Figure 1D), and $\mathrm{CKB}$ protein in tumors was observed (Figure 1E). Notably, protein extracts were prepared from whole tumors, containing proteins expressed by tumor epithelial cells and the stroma, likely minimizing the total reduction in CKB because only the tumor epithelium lacks HIF- $1 \alpha$.

\subsection{CKB Levels Are Correlated with Shortened Regression-Free Survival}

The Cancer Genome Atlas (TCGA) database was queried to compare normalized CKB mRNA expression in breast cancer patients (Figure $1 \mathrm{~F}$ ). $C K B$ is expressed in all subtypes, with enrichment in patients with HER2+ breast cancer relative to basal-like or luminal A subtypes. Comparing regression-free survival (RFS) using KMPlotter, high CKB mRNA expression correlated with decreased RFS regardless of subtype (Figure 1F). In basal breast cancers, this hazard ratio increased (Figure 1F). Although limited breast cancer cases were available to query at the protein level, high levels of CKB were also significantly correlated with reduced overall survival (OS) (Figure 1G).

\subsection{Knockdown of Ckb Impairs Cell Invasion}

To determine whether CKB impacts metastasis to impact overall survival, we generated $C k b$ loss-of-function models in PyMT cells using shRNA-mediated gene knockdown (KD). Two independent shRNAs produced $>70 \%$ gene KD (hereafter referred to as "sh59" and "sh61", Supplementary Figure S2A). Recombinant lentivirus particles produced for each shRNA construct were used to transduce HIF-1 WT cells, resulting in $>70 \%$ reductions in $C k b$ mRNA and CKB protein compared with either HIF-1 WT or empty vector (HIF-1 WT+ EV) transduced cells (Figure 2A,B and Supplementary Figure S2A,B). Each shRNA KD pool represents hundreds of colonies surviving selection. Through qPCR and Western blotting, the sh61 $C k b$ KD pool exhibited the greatest reduction in mRNA and protein (Figure 2A,B). Deletion of $C k b$ did not affect HIF-1 $\alpha$ expression (Supplementary Figure S2C). 


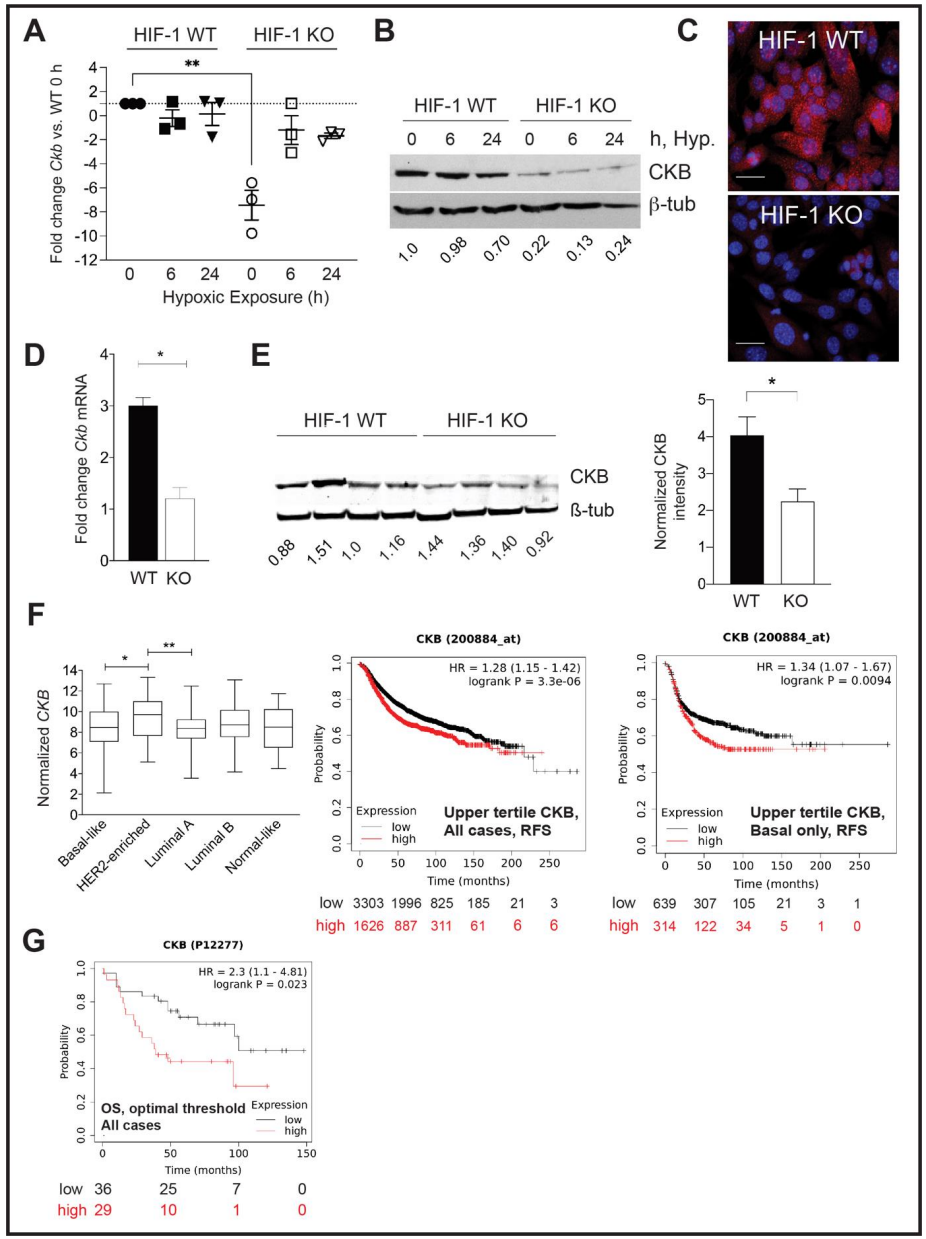

Figure 1. CKB expression in HIF-1 WT and KO PyMT cells and in end-stage tumors, and correlation with prognosis in clinical datasets. (A) Scatter plot of the mean fold change \pm SEM in Ckb mRNA levels relative to HIF-1 WT cells at normoxia (0h of hypoxic exposure). Each data point represents the mean of 3 technical replicates for an independent qPCR assay from a biological replicate experiment, and the overall mean of three biological replicates is shown. (B) PyMT cells were grown to $80 \%$ confluence and subjected to hypoxic culture for either $6 \mathrm{~h}$ or $24 \mathrm{~h}$, or cells were continuously cultured at normoxia, such that the $0 \mathrm{~h}$ sample was harvested on the same day as the $24 \mathrm{~h}$ hypoxic sample. (A) Representative Western blot for CKB or $\beta$-tubulin (loading control) is shown. (C) Immunostaining for CKB (red) in HIF-1 WT and KO cells, counterstained with DAPI. Images were captured at $630 \times$ magnification (scale bar indicates $20 \mu \mathrm{m}$ ). (D) Ckb mRNA levels were compared in end-stage HIF$1 \mathrm{WT}$ and $\mathrm{KO}$ tumors by qPCR. Data are expressed as the overall mean fold change $\pm \mathrm{SEM}$ between WT and KO tumors; the KO sample was set to a fold change of 1.0 in each experiment. All data were first normalized for epithelial content based on $\operatorname{Krt18}(n=3$ tumors/genotype/experiment). (E) Western blotting for CKB comparing four independent tumors per HIF genotype (each harvested at similar volumes). The top half of the blot was blotted for $\mathrm{CKB}$, and the lower portion was blotted for $\beta$-tubulin. Blots were imaged on a LiCor Odyssey system and CKB expression was compared in HIF-1 WT versus KO tumors after normalization to $\beta$-tubulin. The bar graph shows the normalized CKB intensity \pm SEM per genotype. (F) (Left) TCGA was queried for CKB mRNA expression levels among breast cancer subtypes, as defined by PAM50. $\log _{2}$-normalized CKB expression is plotted, along with the 95\% confidence interval and standard deviation. (Right) KM Plotter was used to plot the probability of RFS when patients were stratified by low (lowest-to-middle tertile) or high (upper tertile) expression of CKB mRNA levels (200884_at); plots are shown for either all breast cancer cases, or for basal breast cancer cases only. (G) OS is lower when CKB protein levels (P12277) are high (expression threshold optimized by KMPlotter). All images were directly exported from the KMPlotter tool. 


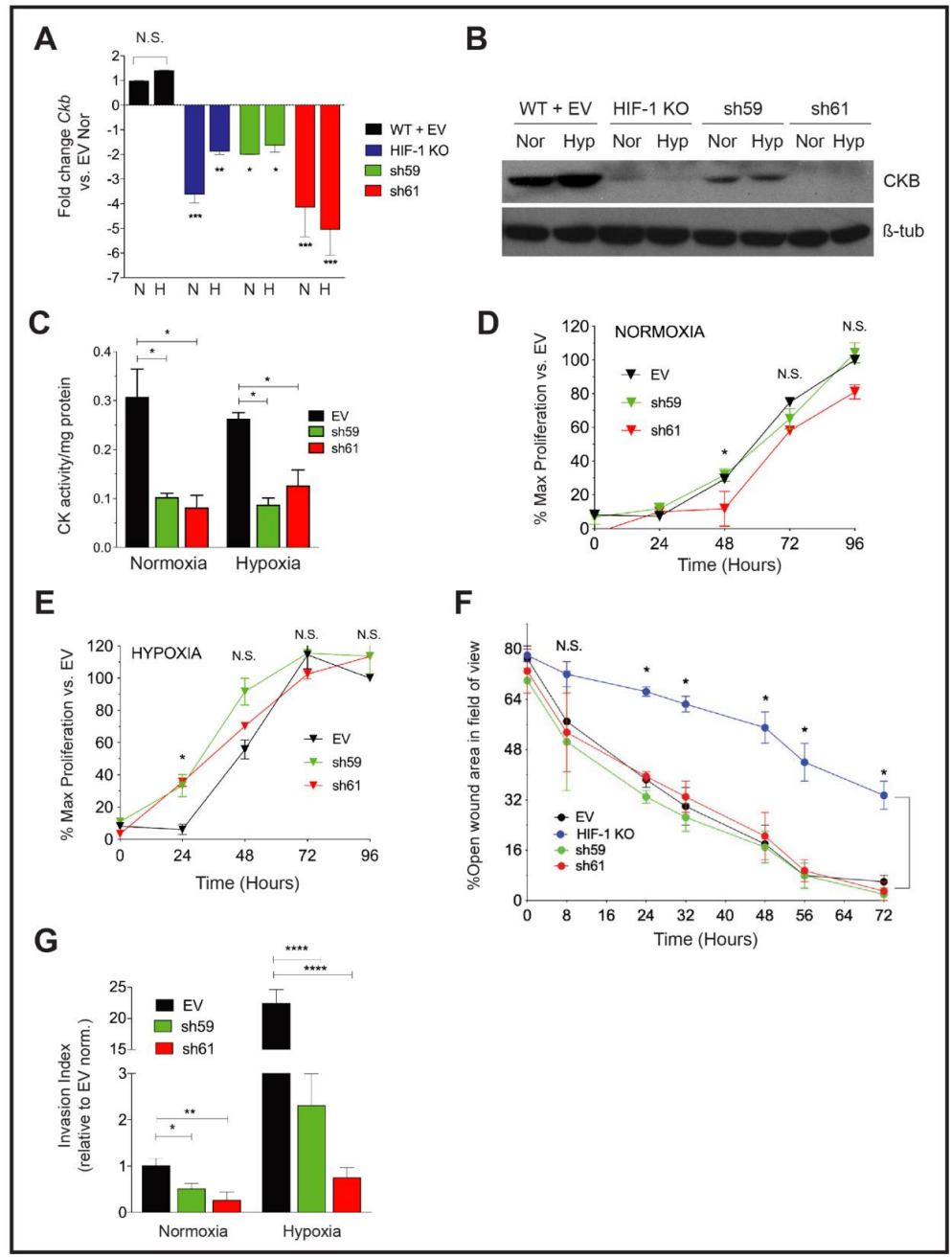

Figure 2. Effect of $C k b$ knockdown in PyMT cells upon cell growth and invasion. (A) The mean fold change \pm SEM in Ckb mRNA expression levels in HIF-1 KO cells and in shRNA KD pools (sh59 or sh61) relative to empty vector $(\mathrm{WT}+\mathrm{EV})$ cells as measured by qPCR. Cells expressing the sh61 shRNA showed the greatest reduction in $C k b$ mRNA levels. (B) PyMT cells were grown to $80 \%$ confluence and subjected to normoxic or hypoxia culture for $6 \mathrm{~h}$ and immunoblotted for CKB or $\beta$-tubulin (loading control). Changes in CKB protein are consistent with changes observed by qPCR, with sh61 KD cells showing the greatest reduction in CKB expression. (C) $\mathrm{CK}^{\text {act }}$ was measured in whole cell extracts prepared from PyMT EV, sh59 or sh61 cells cultured at normoxia or hypoxia (6 h). Data shown are representative of three biological replicate experiments. (D,E) Growth curves of PyMT EV, sh59 or sh61 cells cultured at normoxia (D) or hypoxia (E) in growth medium supplemented with $2 \%$ FBS. Cell proliferation was measured in replicate plates at each time point $(24,48,72$ or $96 \mathrm{~h})$ using the WST-1 assay. For both oxygen tensions, the overall mean of the percentage of proliferating cells relative to EV cells at $\mathrm{t}=0 \mathrm{~h} \pm \mathrm{SEM}$ is presented, calculated as the average of mean cell number for mboxemphn $=3$ technical replicates/time point/genotype as observed over three biological replicate experiments. All data were analyzed by two-way ANOVA; N.S. = not significant. (F) PyMT EV, HIF-1 KO, sh59 KD, and sh61 KD cells were seeded into 6-well dishes such that they would be $100 \%$ confluent the next day. Following wounding, the percentage of open wound area in each field of view was measured and expressed as a ratio per the total area of the field of view. Data were analyzed by two-way ANOVA with a Bonferroni correction post-test. Data are representative of three biological replicate experiments. (G) The overall mean fold change in the invasion index after data were normalized to EV cells cultured at normoxia (fold change set to 1.0; $n=3$ three independent biological replicate experiments). Data were analyzed by ANOVA with a Bonferroni post-test. 
To determine whether the loss of $\mathrm{CKB}$, only one isoform of the four creatine kinases in the cell, impacted total creatine kinase (CK) enzymatic activity, $C K$ activity $\left(\mathrm{CK}^{\text {act }}\right)$ levels were compared in extracts from PyMT EV and $C k b$ KD cells. Measuring $\mathrm{CK}^{\text {act }}$ is also important to predict sensitivity to cyclocreatine $(\mathrm{cCr})$. Cells with very low $\mathrm{CK}^{\text {act }}$ (0.01-0.05 $\mathrm{U} / \mathrm{mg}$ protein) are resistant or refractory to $\mathrm{cCr}$, whereas cells with high $\mathrm{CK}$ activity are $\mathrm{cCr}$-responsive $(>0.10 \mathrm{U} / \mathrm{mg}$ protein) $[45,46]$. Independent of oxygen tension, loss of $\mathrm{CKB}$ reduced $\mathrm{CK}^{\text {act }}$ by approximately threefold in sh59 (data not shown) and in sh61 KD cells (Figure 2C).

Cell proliferation was compared in either normoxia or hypoxia conditions. At normoxia, there was a slight decrease in growth rate in sh61 KD cells, beginning at $48 \mathrm{~h}$ (Figure 2D). However, at hypoxia, cell proliferation was only significantly decreased in sh61 KD cells at $24 \mathrm{~h}$ (Figure 2E). There were no significant changes in proliferation observed between EV and sh59 KD cells. Overall, the deletion of $\mathrm{Ckb}$ had minor effects on PyMT cell proliferation, similar to observations for PyMT HIF-1 KO cells [9].

We next compared breast cancer cell motility using the wound healing assay. There was no significant difference in wound closure between PyMT EV control cells and either sh59 or sh61 KD cells; as expected, HIF-1 KO cells migrated significantly slower (Figure 2F). In contrast, invasion potential was significantly inhibited by $C k b \mathrm{KD}$ at normoxia. Inhibition was more pronounced during hypoxia, with a $>10-20$-fold reduction in invasion for shRNA KD cells relative to EV cells (Figure $2 \mathrm{G}$ ).

\subsection{Loss of CKB Represses Glycolysis and Oxidative Phosphorylation}

PyMT $C k b$ KD cells produced significantly less intracellular ATP than EV cells (Figure 3A). Metabolic activity was further characterized by Seahorse bioanalyzer assays. The extracellular acidification rate (ECAR), a measure of glycolytic activity, was reduced in either sh59 or sh61 KD cells (Figure 3B-D). At the peak ECAR, glycolysis was repressed for each Ckb KD pool (Figure 3C), but only sh61 KD cells exhibited a reduction in glycolytic capacity (Figure 3D). Non-glycolytic acidification was also reduced in each KD pool (Figure 3E). These results are consistent with data from ovarian cancer cells; CKB is required for glycolysis [20]. In contrast, only the sh61 KD pool exhibited deficits in the oxygen consumption rate (OCR) (Figure 3F-H). Basal respiration levels and maximum respiration were reduced in the sh61 KD pool (Figure 3G,H), although there was a non-significant trend in reduction for sh59 cells. ATP levels were significantly reduced in both shRNA KD pools (Figure 3I).

Mouse CKB (mCKB) was stably transfected into HIF-1 KO PyMT cells to determine whether the re-expression of $C K B$ would rescue invasion. The percentage of cells invading through ECM increased when CKB was re-expressed (Figure 4A). CKB was also ectopically expressed in a highly invasive TNBC model, MDA-MB-231 cells, which do not express detectable levels of CKB protein by immunostaining (data not shown) or by immunoblotting. After transient transfection, the percentage of invading cells increased almost threefold (Figure 4B), with similar results when mCKB was stably expressed (data not shown). Next, MDA-MB-231-NucLight Red (NR) cells, in which nuclei are labeled with a dye to allow for real-time imaging during chemotaxis, were transiently transfected with vector or $+\mathrm{mCKB}$. Cells were exposed to reduced serum overnight ( $2 \%$ FBS) and then seeded into ClearView plates and attracted towards 10\% FBS. Over-expression of mCKB in MDA-MB-231-NR cells dramatically increased chemotactic potential (Figure 4C). 


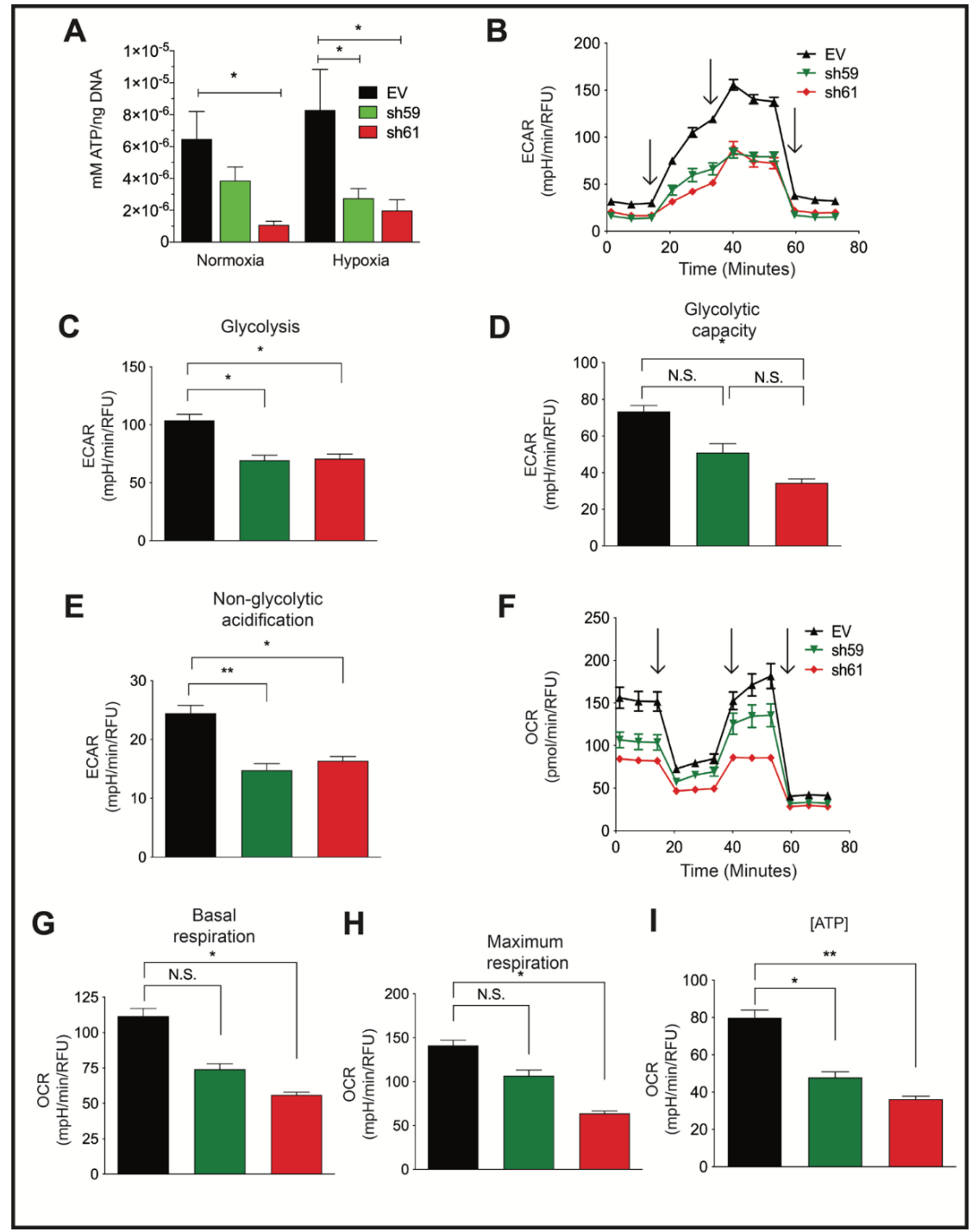

Figure 3. $C k b$ knockdown in PyMT cells reduces ATP levels and impairs both glycolysis and mitochondrial respiration. (A) PyMT EV, sh59 and sh61 cells were plated in triplicate and grown to $80 \%$ confluence prior to normoxic or hypoxic culture $(24 \mathrm{~h})$. Cells were harvested, washed with ice-cold PBS, and immediately lysed on the plate for comparison of the intracellular ATP levels by a bioluminescent assay, and data were normalized to total DNA content. The mean ATP concentration $(\mathrm{mM})$ per ng of DNA $\pm \mathrm{SEM}$ is shown ( $n=3$ technical replicates per cell line/oxygen tension). The data shown are representative of three independent biological replicates. (B-I) PyMT EV, sh59 Ckb $\mathrm{KD}$, and sh61 $\mathrm{Ckb} \mathrm{KD}$ cells were profiled for metabolic activity using Seahorse bioanalyzer assays (Glycolysis Stress or Mito Stress test kits) to measure changes in parameters associated with either ECAR, panels (B-E), or with mitochondrial respiration (OCR, panels $(\mathbf{F}-\mathbf{I})$ ). The black arrows $(\mathbf{B}, \mathbf{F})$ indicate when injections occurred during the assays. Changes were observed in ECAR plotted over time (B), peak glycolysis (C), glycolytic capacity (D), non-glycolytic acidification (E), OCR over time $(\mathbf{F})$, basal respiration $(\mathbf{G})$, maximum respiration $(\mathbf{H})$, and ATP-linked respiration (I) in sh61 Ckb KD cells. For some of the measured outputs, there were also significant changes observed in sh59 Ckb KD cells. Panels $(\mathbf{B}, \mathbf{F})$ are representative of three independent experiments. For panels $(\mathbf{C}-\mathbf{E}, \mathbf{G}-\mathbf{I})$, the bar graphs represent the overall mean of three independent experiment means across $n=6$ technical well replicates/genotype/experiment. Each genotype of cells was randomly plated in different patterns during each independent experiment to minimize any potential effects of plate well location on measurements. 

Invasion

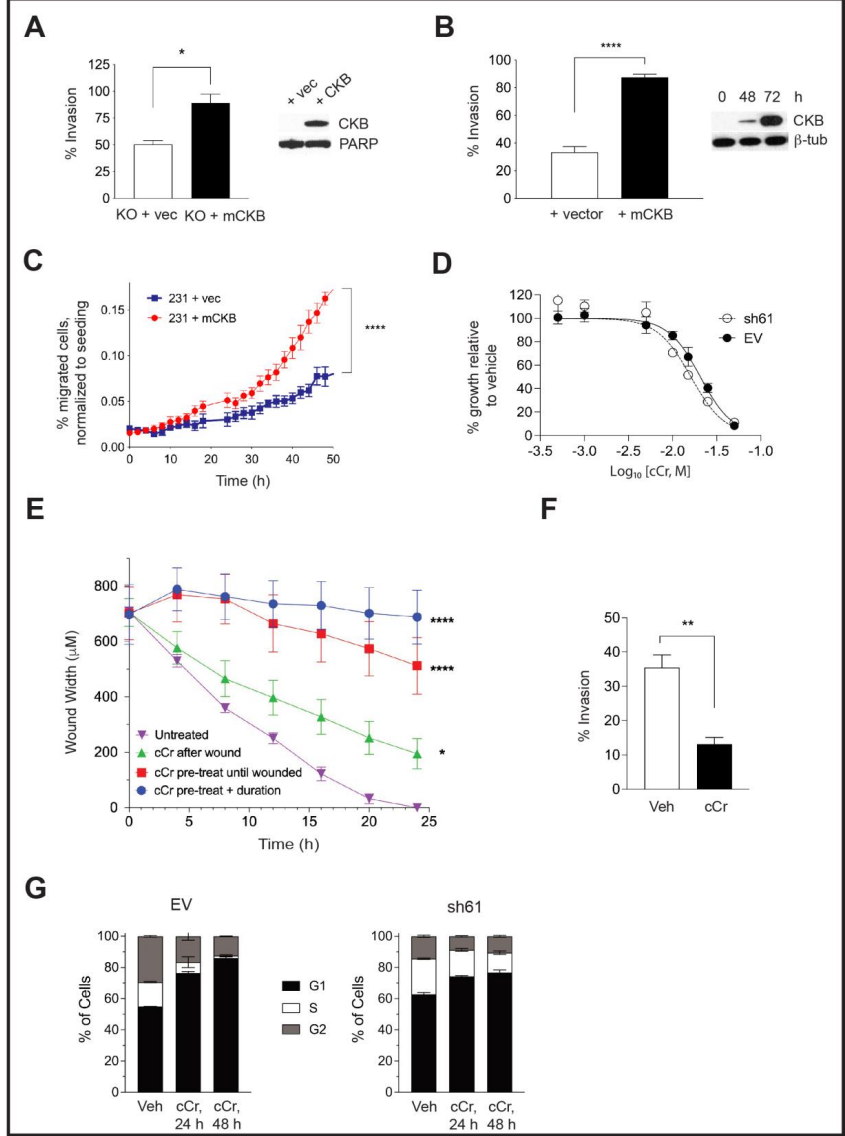

Figure 4. Ectopic expression of CKB in HIF-1 KO PyMT cells or in human MDA-MB-231 TNBC cells enhances cell invasion, but cCr treatment represses wound healing, invasion, and cell cycle progression. (A) The percentage of invading cells was compared between PyMT HIF-1 KO + vector control (+vec) and PyMT HIF-1 KO + mCKB (+CKB) cells over three biological experiments; the overall mean \pm SEM is shown. The insert shows CKB expression by Western blotting relative to total PARP (loading control). (B) The percentage of invading cells in MDA-MB-231 TNBC cells transfected with vector alone (+vector) or with $\mathrm{mCKB}(+\mathrm{mCKB})$; cells were plated for invasion assays $72 \mathrm{~h}$ post-transfection, when CKB levels were maximally expressed (Western blot insert, $\beta$-tubulin as a loading control). (C) Chemotaxis assays were performed in transiently transfected MDA-MB-231-NR cells using IncuCyte ClearView plates. The mean percentage of migrated cells/total cells seeded was compared between genotypes over time during chemoattraction to $10 \%$ FBS. Data are representative of two independent experiments. (D) Cells were exposed to increasing doses of cCr, as described in the Materials and Methods and imaged for $96 \mathrm{~h}$. Percentage growth inhibition was set relative to vehicle control and then plotted vs. $\log$ of the molar concentration and fitted with a nonlinear regression curve analysis. The graph is representative of at least 3 independent biological replicates. (E) PyMT EV cells were plated onto ImageLock plates. Then, cells were either pre-treated with $\mathrm{cCr}$ prior to wounding and cCr added post-wounding; cells were pre-treated with cCr prior to wounding, but $\mathrm{CCr}$ removed post-wounding; or fresh media with cCr was added only after wounding. Data are representative of at least two biological replicates. (F) PyMT EV cells were seeded in an invasion assay in which cells in the upper chamber were exposed to either vehicle or to $25 \mathrm{mM} \mathrm{cCr}$ and then cultured for $48 \mathrm{~h}$. (G) PyMT EV or sh61 cells were treated with $25 \mathrm{mM} \mathrm{cCr}$ for either $24 \mathrm{~h}$ or $48 \mathrm{~h}$, and cell cycle analysis was performed by PI staining to assess changes in cell cycle progression. The mean \pm SEM is shown for each phase of the cell cycle ( $n=3$ technical replicates/genotype/time point). Data are representative of three independent experiments. 
To test whether treatment with cyclocreatine (cCr) would mimic a loss of CKB function, $\mathrm{EV}$ and sh61 $\mathrm{Ckb}$ KD PyMT cells were treated with increasing concentrations of $\mathrm{CCr}$ for $96 \mathrm{~h}$ and growth inhibition was evaluated. We had expected to observe that $\mathrm{cCr}$ sensitivity would be reduced in $C k b$ KD cells; however, the dose response curves were overlapping. The $\mathrm{IC}_{50}$ values in EV and sh61 cells at $96 \mathrm{~h}$ were $13.73 \pm 4.33 \mathrm{mM}$ and $16.43 \pm 2.98 \mathrm{mM}$, respectively (Table 1). Then, $15 \mathrm{mM}$ and $25 \mathrm{mM} \mathrm{cCr}$ doses were used in short-term biological assays (24-48 h duration); thus, we confirmed that these doses do not induce extensive cell death in EV or HIF-1 KO cells compared with vehicle treatment, although the basal level of cell death is higher in HIF-1 KO cells (Supplementary Figure S3A,B).

Table 1. Cyclocreatine (cCr) $\mathrm{IC}_{50}$ values in PyMT ER-negative cells. $\mathrm{IC}_{50}$ values $\pm \mathrm{SEM}$ were determined at $96 \mathrm{~h}$, as described in the Materials and Methods section. $\mathrm{IC}_{50}$ values for independent experiments were calculated using non-linear regression and variable slope fit in Prism 9.0. Results from independent experiments were averaged to report the mean $(n=6$, WT; $n=6$, HIF-1 KO; $n=4$, $\mathrm{EV} ; n=6$, sh61).

\begin{tabular}{cccc}
\hline HIF-1 WT & HIF-1 KO & EV & sh61 CKB KD \\
\hline $16.76 \mathrm{mM} \pm 4.47$ & $15.44 \mathrm{mM} \pm 3.95$ & $13.73 \mathrm{mM} \pm 4.33$ & $16.43 \mathrm{mM} \pm 2.98$ \\
\hline
\end{tabular}

We tested cCr for anti-metastatic activity in a high-throughput wound assay. Either pre-treatment of PyMT EV cells with cCr prior to seeding, or adding cCr only after the scratch was applied, inhibited wound healing (Figure 4E). The most potent repression occurred when cells were pre-treated with $\mathrm{cCr} 24 \mathrm{~h}$ prior to wounding and then $\mathrm{CCr}$ was re-added during healing. However, $\mathrm{cCr}$ pre-treatment before wounding without adding cCr post-scratch also significantly delayed wound healing (Figure 4E). Exposure of EV cells to $\mathrm{cCr}$ also represses invasion through Matrigel (Figure 4F). Overall, small molecule inhibition of the CK pathway via cCr mimics the loss of $\mathrm{CKB}$ function.

The chemotherapeutic potential of $\mathrm{cCr}$ is also related to its ability to block cell cycle progression. Short-term treatment with $\mathrm{cCr}$ has reversible effects on the cell cycle, whereas long-term treatment leads to cell death [47]. EV cells treated with cCr accumulated in the G1 phase after $24 \mathrm{~h}$, with a corresponding reduction in the percentage of cells in the S-phase; these results were exacerbated at $48 \mathrm{~h}$ (Figure $4 \mathrm{G}$ ). In contrast, sh61 KD cells In contrasted smaller increases in the G1 phase or decreases in the S-phase, and the differences between $24 \mathrm{~h}$ and $48 \mathrm{~h}$ of $\mathrm{cCr}$ treatment were negligible (Figure $4 \mathrm{G}$ ).

\subsection{Loss of Ckb Suppresses Tumor Growth and Inhibits Lung Metastases}

We compared the growth of mammary tumors regenerated from the orthotopic implantation of PyMT EV, HIF-1 KO, sh59 KD and sh61 KD cells. In contrast to in vitro cell proliferation results, the tumor growth rate was suppressed, and tumor size was highly similar between HIF-1 KO tumors and each Ckb shRNA pool (Figure 5A). There was no significant difference in tumor volume between each shRNA pool. At day 34 post-transplant, the mean tumor volume of EV cells was $\geq 1000 \mathrm{~mm}^{3}$, whereas all other genotypes had reached a maximum volume of $\sim 200 \mathrm{~mm}^{3}$. Decreases in tumor wet weight were similarly observed (Figure 5B). To investigate whether the loss of $C k b$ in the tumor epithelium impacted overall survival, in an independent experiment, all tumors were grown until surgical resection at a similar volume, and animals were housed until moribund due to lung metastases. Animals previously bearing CKB + EV tumors became moribund $>3 \times$ faster than recipients of shRNA KD cells $(\mathrm{HR}=3.681$, Figure $5 \mathrm{C})$. Tumor sections were then immunostained with antibodies to either Ki67, activated caspase-3 or CD31, and areas positive for these markers were quantified. Likely because PyMT EV tumors are highly necrotic, the percentage of positive areas for Ki67+ cells was higher in all of the smaller tumors (HIF-1 KO, sh59 and sh61; Figure 5D). As expected, CD31 levels were decreased in HIF-1 KO tumors relative to EV tumors, whereas a reduction in CD31 was only significant for sh61 KD tumors (Figure 5E). Approximately $9.8 \%$ of EV tumor area was apoptotic. In 
contrast, very low levels of apoptosis were observed for HIF-1 KO tumors $(0.77 \%)$, and apoptosis was lower in shRNA KD tumors compared with EV tumors (Figure 5F).

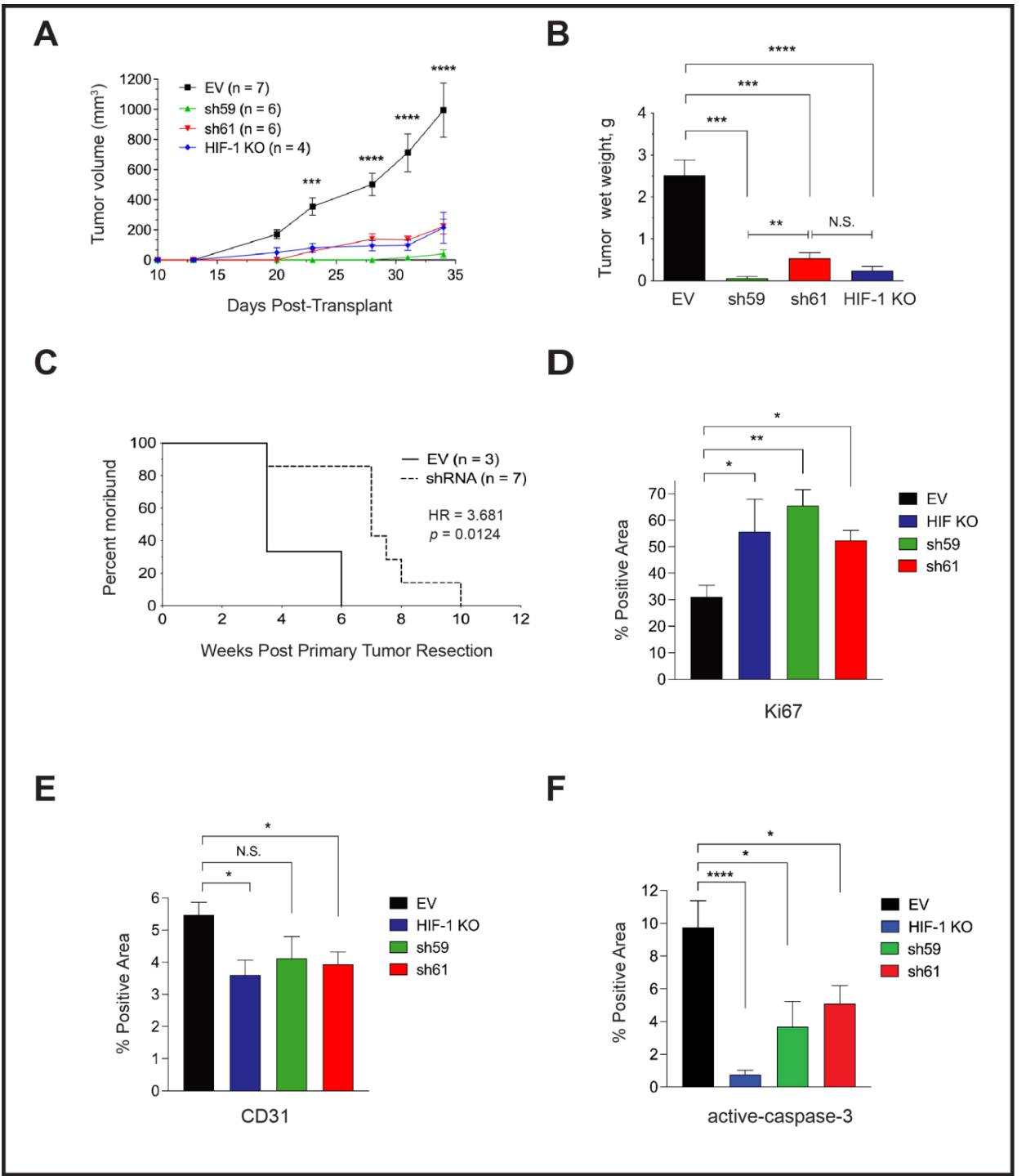

Figure 5. Tumor-cell-intrinsic CKB promotes PyMT primary tumor growth and lung metastasis in vivo, and the deletion of $C K B$ in the tumor epithelium improves overall survival. (A) Growth rate over time after transplantation of PyMT EV, HIF-1 KO, sh59 KD, and sh61 KD cells into the inguinal mammary fat pad of female FVB/Nj recipients. Mean tumor volume $\pm \mathrm{SEM}$ is shown. (B) All tumors harvested at day 34 from panel (A) were weighed to determine the mean wet weight $(\mathrm{g}) \pm \mathrm{SEM}$ at the experiment endpoint. Data in $(\mathbf{A}, \mathbf{B})$ are representative of two independent experiments. $(\mathbf{C})$ The impact of $\mathrm{CKB}$ expression in the PyMT tumor epithelium on the survival of recipients following tumor resection. Mice implanted with PyMT cells (EV or either shRNA KD construct) were subjected to primary tumor resection after tumors grew to similar volumes $\left(\sim 500 \mathrm{~mm}^{3}\right)$, and mice were allowed to survive post-resection until moribund due to lung metastasis. Mice were removed from the study when panting due to lung metastasis, or if bodyweight decreased by $>15 \%$. The morbidity hazard ratio (HR) was 3.68-fold higher when $\mathrm{FVB} / \mathrm{Nj}$ recipients bore $\mathrm{Ckb}$ WT tumors ( $n=3$ mice for EV and $n=7$ total mice for $C k b$ shRNA knockdown, representing either sh59 KD or sh61 KD tumors). (D-F) Immunostaining of PyMT EV ( $n=5$ tumors), HIF-1 KO ( $n=4$ tumors), sh59 KD ( $n=4$ tumors) or sh61 KD ( $n=5$ tumors) sections to enumerate Ki67 (D), CD31 (E) or activated-caspase 3. (F) The mean \pm SEM of the percentage (\%) of the positive area of whole tumor sections is reported for each genotype. 


\subsection{Either Ckb deletion or Systemic Treatment with Cyclocreatine Blocks Lung Metastasis}

To explore whether $C k b$ knockdown blocks the latter stages of the metastatic cascade, PyMT EV, sh59 or sh61 KD cells were injected into the tail vein to generate lung metastases. Lungs of mice injected with EV cells were filled with large metastases visible to the naked eye, whereas no surface metastases were observed for sh61 KD cells (Figure 6A). A strong repression of metastasis was observed for both shRNA Ckb KD pools, but there was no significant difference between the two pools (Figure 6A).

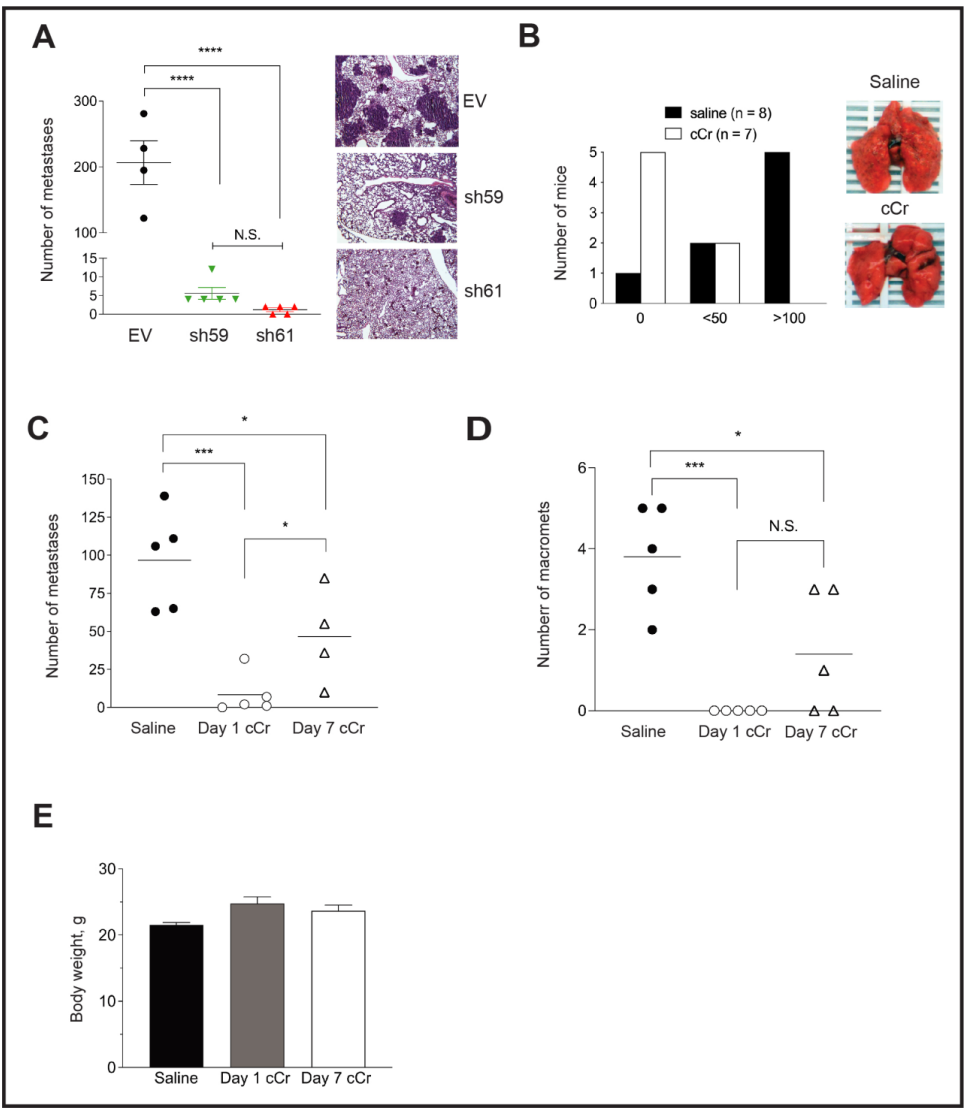

Figure 6. Knockdown of $C k b$ in the PyMT tumor epithelium or systemic $c C r$ therapy decreases lung metastasis burden. (A) PyMT EV, sh59 KD or sh61 KD cells were injected into the tail vein of female FVB/ Nj recipients. After 21 days, mice were euthanized and lungs were harvested for metastasis evaluation after lung inflation through the trachea with PBS. The number of metastases was compared across genotypes; the scatter plot shows the burden of individual lungs as the mean \pm SEM. Corresponding H\&E-stained images of lungs representative of the genotype mean are shown $(400 \times$ magnification). Data are representative of two independent experiments. (B) EV PyMT cells were injected into the tail vein of female FVB/ $\mathrm{Nj}$ recipients. The next day, treatment with either vehicle (saline, IP, daily) or $\mathrm{CCr}(1 \mathrm{~g} / \mathrm{kg}$ in saline, IP, daily) was initiated. After 21 days, the mice were euthanized, and lungs were harvested after inflation with PBS. The total number of surface metastases was counted under a dissecting scope. Most of the mice treated with $\mathrm{cCr}$ (5 of 7) did not develop detectable metastases, although 2 mice in each cohort $(2 / 8$, saline and $2 / 7, \mathrm{cCr})$ developed fewer than 50 metastases. Only in the saline group did the majority of mice develop metastases throughout the lung, with $>100$ lesions present $(5 / 8$ mice; $\chi 2=7.634, p=0.022)$. Images of whole lungs photographed immediately post-dissection are shown. (C,D) Comparison of total metastases present per lung $(\mathbf{C})$, or the number of macro-metastases per lung $(\mathbf{D})$ when mice were treated with vehicle, or when $\mathrm{cCr}$ was administered at either day 1 (Day $1 \mathrm{cCr}$ ) or when $\mathrm{cCr}$ therapy began at day 7 after the tail vein injection (Day $7 \mathrm{cCr}$ ). All lungs were harvested at day 21 post-injection. (E) The mean bodyweight of the mice treated with saline (vehicle) or $\mathrm{cCr}$ from panels $(\mathbf{C}, \mathbf{D})$. 
Next, we determined whether treatment with $\mathrm{cCr}$ inhibits lung colonization or the growth of pre-established lung micro-metastases. PyMT EV cells were injected into the tail vein and allowed to seed the lungs for $24 \mathrm{~h}$. Mice then received daily treatment with $\mathrm{cCr}$ at a dose of $1 \mathrm{~g} / \mathrm{kg}$ or vehicle $(0.9 \%$ saline, IP) for 21 days. The surface of lungs from vehicle-treated mice was covered with metastases, whereas very few metastases were visible in the $\mathrm{cCr}$ cohort (Figure $6 \mathrm{~B}$ ). The majority of mice treated with vehicle developed metastases $(7 / 8$, or $87.5 \%)$, and $5 / 8$ mice $(62.5 \%)$ treated with saline developed $>100$ lesions. In contrast, zero metastases were observed in $5 / 7$ mice in the $\mathrm{cCr}$ cohort $(71.4 \%)$, and 2 mice in each cohort developed fewer than 50 metastases $\left(\chi^{2}, p<0.05\right)$. These results were replicated in an independent experiment, and a third cohort was added in which the administration of $\mathrm{cCr}$ therapy was delayed by 7 days, a time after which lung micrometastases had formed, such that therapy was then given for a total of 14 days. For mice treated with $\mathrm{cCr}$ beginning at day 1 , the mean number of metastases was reduced by over tenfold. In contrast, approximately 50\% fewer metastases were detected if cCr therapy began on day 7 (Figure 6C). There were no detectable macro-metastases in the day $1 \mathrm{cCr}$ cohort, versus 3.8 in the saline group or 1.4 in the day $7 \mathrm{cCr}$ cohort (Figure 6D). Over the course of treatment, mice did not develop gross symptoms of toxicity and there was no significant difference in body weight when animals were treated for either 14 (day $7 \mathrm{cCr}$ ) or 21 consecutive days (day $1 \mathrm{cCr}$ ) (Figure 6E).

\subsection{Addition of Cyclocreatine to Paclitaxel or Doxorubicin Enhances Growth Inhibition}

In a broad panel of cancer cell lines, $c$ Cr repressed cell growth with a similar efficacy as conventional agents, including cyclophosamide, doxorubicin, or 5-FU [25,45,46,48]. Rat mammary adenocarcinoma tumor growth was enhanced when $\mathrm{cCr}$ (IV, IP) was paired with either cyclophosphamide, doxorubicin, or 5-FU [25], or if the rats were fed chow supplemented with $1 \% \mathrm{cCr}$ [49]. In pancreatic cancer and in myeloid leukemia, $\mathrm{cCr}$ monotherapy inhibits metastasis to distant organs [28,50]. Finally, in HER2+ trastuzumabsensitive or -resistant breast cancer models, pairing $\mathrm{cCr}$ with traszutumab represses cell growth via the inhibition of CKMT1 [51]. Based on these observations, we sought to specifically determine in ER-negative breast cancer cell line models if cCr therapy was additive to, or synergistic with, paclitaxel (Taxol) or doxorubicin (DOX), two widely used agents to treat stage IV breast cancer, using a formal isobole testing method [39].

First, we compared CKB expression levels in a panel of breast cancer cell lines representing various molecular subtypes (Figure 7A and Supplementary Figure S4). MDAMB-231 and SUM-159 (TNBC) and T47D (ER+, luminal B) cells did not express detectable $\mathrm{CKB}$ levels, whereas expression was variable in the other cell lines. CKB protein was most abundant in MDA-MB-453 cells (TNBC), which also express low levels of HER2+ protein, although not above the clinical cutoff for designating HER2-amplification [52]. CKB was moderately expressed in MDA-MB-468 and BT549 TNBC cells (Figure 7A), which expressed similar CKB levels to murine PyMT cells (Figure 1B or Figure 7A). AU565 (HER2+), CAMA1 (ER+, luminal B), HCC2157 (TNBC) and HCC70 (TNBC) also expressed moderate levels of CKB. MDA-MB-436 (TNBC) cells expressed relatively low levels of CKB protein (Supplementary Figure S4). 


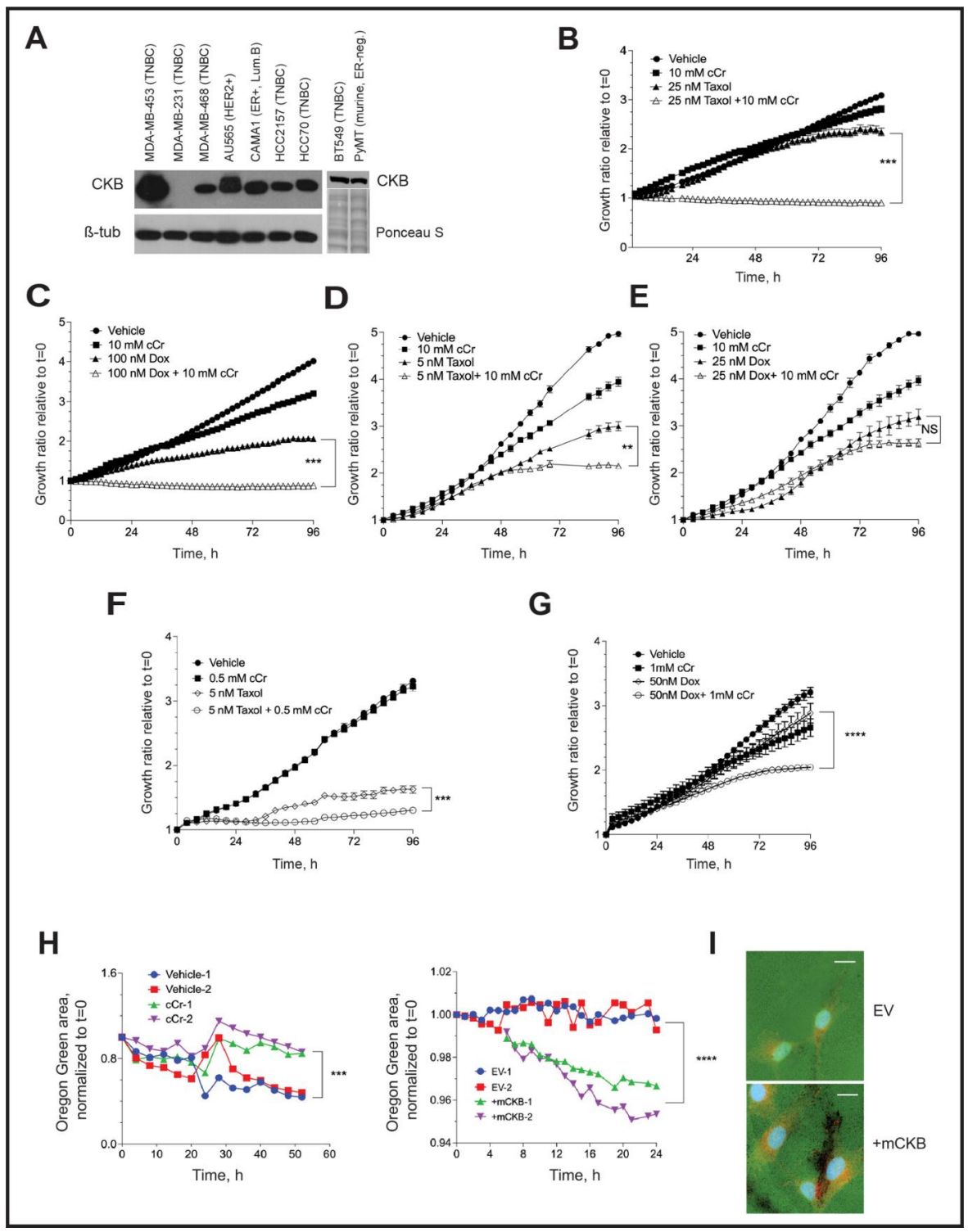

Figure 7. Cyclocreatine is synergistic with, or additive to, two conventional chemotherapies, and cyclocreatine inhibits the formation of invadopodia. (A) (Left) Western blotting for endogenous CKB protein in a panel of human breast cancer cell lines ( $\beta$-tubulin, loading control). (Right) Western botting for CKB protein in BT549 TNBC cells and HIF-1 WT PyMT cells in a separate blot. BT549 cells express similar levels of CKB protein to PyMT HIF-1 WT cells; equivalent loading is indicated by Ponceau $S$ staining. (B-G) The growth ratio (all treatments are normalized to their respective $t=0$ cell density) over time when human MDA-MB-468 TNBC cells (B,C), BT549 TNBC cells (D,E) or MDA-MB-453 TNBC cells $(\mathbf{F}, \mathbf{G})$ are cultured in the presence of vehicle, $\mathrm{CCr}$ alone, or cCr with Taxol $(\mathbf{B}, \mathbf{D}, \mathbf{F})$ or doxorubicin $(\mathbf{C}, \mathbf{E}, \mathbf{G})$ for $96 \mathrm{~h}$. H. Loss of Oregon Green-conjugated gelatin was measured in the IncuCyte S3 live-cell imager after seeding cells onto gelatin-coated coverslips in the presence of an MMP inhibitor, and then the replacement of growth medium with or without $\mathrm{cCr}$, as described in the Materials and Methods. Quantification data over time are shown for vehicle-treated versus $\mathrm{cCr}$ treated BT549 cells ((H), Left panel) or for MDA-MB-231 empty vector (EV) or MDA-MB-231 +mCKB cells ((H), Right panel). Two coverslips were measured simultaneously at each time point across each coverslip/well ( $n=16$ independent images/coverslip/timepoint). Data are representative of three independent experiments. (I) Example immunostaining images of invadopodia at experimental endpoint co-stained with cortactin (red) and DAPI (630× magnification, scale bar represents $20 \mu \mathrm{M})$. All images were captured with identical laser intensity and exposure settings. 
Three TNBC cell line models were selected for evaluating the efficacy of $\mathrm{cCr}$ monotherapy versus combination with paclitaxel or DOX, including MDA-MB-468 (CKB moderate) BT549 (CKB moderate) and MDA-MB-453. (CKB high). BT549 cells also formed invadopodia in vitro [53]. The estimated $\mathrm{IC}_{50}$ doses of $\mathrm{cCr}$ and each chemotherapy were determined by phase confluence assays, as described in the Materials and Methods (Table 2). Isobole assays evaluated whether combination therapy was likely to be additive or synergistic (Table 3).

Table 2. Calculation of monotherapy $\mathrm{IC}_{50}$ values in human $\mathrm{TNBC}$ cell lines. $\mathrm{IC}_{50}$ values $\pm \mathrm{SEM}$ were determined at $96 \mathrm{~h}$, as described in the Materials and Methods. $\mathrm{IC}_{50}$ values for independent experiments were calculated using non-linear regression and variable slope fit in Prism 9.0. Results from independent experiments were averaged to report the mean ( $n=4$ replicates/cell line/drug).

\begin{tabular}{cccc}
\hline Cell Line & $\begin{array}{c}\text { cCr } \\
\mathbf{C}_{\mathbf{5 0}}, \mathbf{~} \mathbf{m}\end{array}$ & $\begin{array}{c}\text { Taxol } \\
\mathbf{C}_{\mathbf{5 0}}, \mathbf{n M}\end{array}$ & $\begin{array}{c}\text { DOX } \\
\mathbf{C}_{\mathbf{5 0}}, \mathbf{n M}\end{array}$ \\
\hline MDA-MB-468 & $19.15 \pm 3.06$ & $11.16 \mathrm{nM} \pm 2.94$ & $343.6 \pm 126.6$ \\
\hline BT549 & $22.38 \pm 1.47$ & $3.82 \pm 0.44$ & $28.28 \pm 3.68$ \\
\hline MDA-MB-453 & $6.10 \pm 1.48$ & $6.03 \pm 1.75$ & $60.39 \pm 11.53$ \\
\hline
\end{tabular}

Table 3. Combination indices calculated for human TNBC cell lines pairing cCr with either Taxol or DOX. Isobole studies were performed, and data representative of 2 independent isobole assays are shown.

\begin{tabular}{|c|c|c|c|c|}
\hline \multirow{2}{*}{$\begin{array}{c}\text { TNBC Models } \\
\text { Cell Line }\end{array}$} & \multicolumn{2}{|c|}{$\begin{array}{c}\text { Taxol @ } \mathrm{IC}_{50} \\
+\mathrm{cCr} @ \mathrm{IC}_{30} \\
\text { Combination Indices (CI) }\end{array}$} & \multicolumn{2}{|c|}{$\begin{array}{c}\text { DOX @ } \mathrm{IC}_{50} \\
+\mathrm{cCr} @ \mathrm{IC}_{30} \\
\text { Combination Indices (CI) }\end{array}$} \\
\hline & $\underset{\text { CI }}{\text { IC }_{50, \text { TAXOL }}}$ & $\underset{\text { CI }}{\text { IC }_{70, \text { TAXOL }}}$ & $\begin{array}{l}\mathrm{IC}_{50, \mathrm{DOX}} \\
\text { CI }\end{array}$ & $\begin{array}{c}\mathrm{IC}_{70, \mathrm{DOX}} \\
\text { CI }\end{array}$ \\
\hline MDA-MB-468 & 1.06 & 0.52 & 0.61 & 0.39 \\
\hline BT549 & 0.86 & 0.58 & 1.50 & 1.28 \\
\hline MDA-MB-453 & 0.95 & 2.18 & 0.77 & 1.40 \\
\hline
\end{tabular}

In MDA-MB-468 cells, a combination of $10 \mathrm{mM} \mathrm{cCr}$ with $25 \mathrm{nM}$ Taxol was synergistic (combination index, $\mathrm{CI}=0.52$ ), efficiently inhibiting cell growth (Figure 7B). For DOX, $100 \mathrm{nM}$ repressed growth by $\sim 50 \%$, but the addition of $\mathrm{cCr}$ to DOX further inhibited cell growth (Figure 7C); this combination was additive. In contrast, in BT549 cells, cCr was synergistic with a $5 \mathrm{nM}$ dose of Taxol (Figure 7D), but no significant change in cell growth was observed when $\mathrm{cCr}$ was paired with DOX; in fact, isobole studies suggested antagonistic effects of this combination (CI > 1.0) (Figure 7E, Table 3). In MDA-MB-453 cells, the most sensitive model to cCr (Table 2), the combination of either Taxol (Figure 7F) or DOX (Figure $7 \mathrm{G}$ ) with $\mathrm{cCr}$ was synergistic at the $\mathrm{IC}_{50}$ doses of either agent $(\mathrm{CI}=0.95$ and 0.77 , respectively). It has previously been reported that combining $\mathrm{c} C \mathrm{r}$ with Taxol enhances microtubule stability, leading to the synergistic killing of MCF-7 (ER-positive) cells [54]. To establish if this effect is also observed in ER-negative cells, MDA-MB-468 cells were immunostained for alpha-tubulin. Treatment with cCr slightly disrupted the microtubule network and Taxol-stabilized microtubules, but the addition of $\mathrm{cCr}$ to Taxol further stabilized tubulin networks, indicating synergy between $\mathrm{cCr}$ and Taxol (Supplementary Figure S5). The molecular mechanisms of the observed additive effects of $\mathrm{cCr}$ in combination with DOX require further investigation.

\subsection{Invadopodia Formation in TNBC Cells Depends on Creatine Kinase Activity}

To determine if $\mathrm{CKB}$ regulates local invasion through the formation of invadopodia, two human TNBC models were used: MDA-MB-231 and BT549 cells. Invadopodia are 
characterized by the focal degradation of a fluorescent gelatin coating deposited onto glass coverslips prior to cell seeding, in addition to the presence of cortactin [38]. We optimized protocols to image the loss of gelatin by imaging invadopodia assay coverslips submerged into 24-well dishes using a live-cell imager (Figure 7H). Representative experiments of two independent, simultaneously imaged coverslips revealed that treatment of BT549 cells with $\mathrm{cCr}$ inhibited the loss of gelatin over time $(52 \mathrm{~h})$, whereas the ectopic expression of CKB in MDA-MB-231 cells stimulated gelatin loss over $24 \mathrm{~h}$ (Figure $7 \mathrm{H})$. The presence of cortactin in areas of invadopodia formation was validated by immunofluorescence at the end of the imaging (Figure 7I; BT549 images in Supplementary Figure S6A). We also immunostained for $\mathrm{CKB}$ in endpoint invadopodia in MDA-MB-231 +mCKB cells. Representative images comparing empty vector and $+\mathrm{mCKB}$ cells revealed that $\mathrm{CKB}$ protein is detectable at the edges of invadopodia (Supplementary Figure S6B).

\section{Discussion}

Although multiple roles for HIF- $1 \alpha$ in mediating breast cancer phenotypes are welldefined [55], many individual HIF-1 $\alpha$-dependent genes remain to be characterized for their role in breast tumor progression and metastasis in specific breast cancer subtypes. We identified CKB as an HIF-1 $\alpha$-dependent target gene necessary for tumor outgrowth and lung metastasis in the MMTV-PyMT transgenic model of MBC. Higher CKB mRNA or protein levels were also found to be prognostic of reduced relapse-free survival (RFS) across all molecular subtypes of breast cancer. The likelihood of RFS was further decreased for patients diagnosed with basal-like breast cancers. Basal-like and HER2-enriched subtypes exhibit high constitutive expressions of HIF-1 $\alpha$ and HIF-1 target genes [32,56]; therefore, we focused on understanding the function of CKB in ER-negative models.

An HIF-dependent, but not hypoxia-stimulus-dependent, regulation of $C k b$ mRNA and protein levels was observed in PyMT cells. HIF protein stabilization can be induced independently of hypoxia by several growth factor signaling pathways, including EGF and HER2 [57]; thus, the HIF-1-dependent, but not hypoxia-induced, expression of CKB in TNBC may be mediated in this manner. Cell stressors such as low glucose, change in $\mathrm{pH}$, and the production of reactive oxygen species (ROS) all increase HIF-1 $\alpha$ expression [58], and could up-regulate CKB expression independent of hypoxia. In contrast, in ER+ MCF7 breast cancer cells, CKB mRNA levels increased in response to hypoxia. In both models, ChIP assays demonstrated that $\mathrm{CKB}$ is a direct HIF transcriptional target in the breast epithelium.

CKB mRNA and protein levels were also decreased in HIF-1 KO end-stage whole tumors, although the reduction was modest relative to cultured cells. A significant difference in $C k b$ mRNA levels in tumors was observed only after normalization to the epithelial marker K18. HIF-1 loss, and thus, reduced CKB, is targeted only to the tumor epithelium; therefore, a significant proportion of the CKB signal observed in whole tumor extracts is likely derived from the stroma. CKB is expressed in adipose, macrophages and endothelial cells [29,59-61].

The biological activities predominantly impacted in response to $C k b$ shRNA KD were related to metastatic potential, including the repression of invasion through the extracellular matrix (ECM) and reduced lung metastasis. ATP production was also inhibited. Surprisingly, Seahorse analysis revealed decreases in both the glycolytic and mitochondrial respiration (OXPHOS) arms of cellular metabolism, with the most prominent changes observed for sh61 shRNA cells. Glycolytic capacity was reduced by 53\%, basal respiration was reduced by $46 \%$ and maximal respiration was reduced by $55 \%$. Furthermore, the basal and maximum respiration rates of sh61 KD cells were similar (59.9 vs. $63.6 \mathrm{mpH} / \mathrm{min} / \mathrm{RFU}$ ), suggesting an inability to respond to increased demand for energy. We conclude that whereas either cellular proliferation or cell motility can tolerate decreased ATP production when $\mathrm{CKB}$ levels are low, the creatine kinase phosphagen arm is essential to produce the energy necessary for cell invasion and metastatic colonization. In other breast cancer cell types that regulate $\mathrm{CKB}$ in a hypoxia-dependent manner, such as MCF-7 cells, increased 
CKB expression may be necessary to supplement energy production when oxygen is limited and glycolysis is the predominant pathway to generate ATP. It has been suggested that cytosolic CKs interact with the mitochondrial CK isoforms to maintain energy flux [15]. In thermogenic brown fat, CKB directly shuttles between mitochondria and the cytoplasm, directly regulating mitochondrial ATP turnover [61]. CKB deletion in the presence of oxygen impaired energy production through glycolysis and mitochondrial respiration, similar to our observations in ER-negative breast cancers.

Despite minimal changes in proliferation in vitro in response to the loss of $\mathrm{CKB}$, there was a robust decrease in the PyMT Ckb KD tumor growth rate. Remarkably, deletion of this single HIF-1 target gene produced tumors with similar volumes to HIF-1 KO cells, suggesting that tumor-cell-intrinsic CKB directly influences the local surrounding microenvironment to promote tumorigenesis. It is possible that the loss of epithelial-derived CKB disrupts a paracrine network necessary to promote tumor growth. For example, local extracellular secretion of $\mathrm{CKB}$ by colon cancer cells into the liver microenvironment promotes metastatic outgrowth through the extracellular production of phosphocreatine (PCr), which was then imported into tumor cells as an energy source [27]. In this model, implantation of an osmotic pump releasing cCr into peritoneum also repressed liver metastasis [27].

Tail vein assays revealed a significant decrease in lung colonization, either in response to $\mathrm{Ckb} \mathrm{KD}$ or by inhibiting $\mathrm{CK}$ activity with daily cCr systemic treatment. cCr significantly inhibited the formation of lung macro-metastases and the conversion of pre-established micro-metastases to macro-metastases. Overall survival increases when $C k b$ is deleted in tumors re-generated from MTECs orthotopically implanted into the WT mammary fat pad; therefore, it is also clear that $C K B$ is necessary for efficient completion of the entire metastatic cascade, beginning with local invasion. This conclusion is also supported by our observations that the loss of $\mathrm{CKB}$ in PyMT cells impairs invasion, whereas the over-expression of CKB in MDA-MB-231 cells not only enhances chemotaxis and cell invasion, but also promotes invadopodia activity. The apparent relationship between HIF-1, a master regulator of cellular metabolism, and $\mathrm{CKB}$, and the degradation of the extracellular matrix by invadopodia is intriguing. In a proteomics screen to identify factors enriched in invadopodia, multiple HIF-dependent metabolic enzymes were identified, including GAPDH, enolase 1, lactate dehydrogenase (LDH), pyruvate kinase, muscle 2 (PKM2) and phosphoglycerate kinase 1 (PGK1) [62]. Additional studies are warranted to ascertain how the HIF-1 $\alpha$-dependent modulation of CKB expression contributes to each step of the metastatic cascade. Notably, creatine supplementation, which increases creatine kinase flux, is not sufficient to change the primary tumor growth rate, but significantly enhances lung metastasis, including in the 4T1 breast cancer model [63]. Overall, the tight regulation of cellular metabolism by CKs is likely critical for a cell's ability to invade.

Local ATP generation coordinated by CKB to facilitate cell motility was previously suggested for astrocytes and fibroblasts [29]. The direct relationship of creatine flux with ATP levels and cell motility was recently revealed using pancreatic cancer models [28]. In this study, $\mathrm{CKB}$, but not other $\mathrm{CK}$ isoforms, was shown to be a Yes-associated protein (YAP)-responsive mechanosensory responder. In particular, YAP increased CKB expression and $C K$ activity in response to a stiff extracellular environment. Increased expression of YAP promotes breast tumorigenesis, although it is dispensable for normal mammary gland development [64]. Connections between YAP and HIF and CKB are of interest because YAP can induce HIF-1 $\alpha$ [64] through mechanical loading [65], and because hypoxia/HIF-1 can also stimulate YAP activity through 14-3-3-zeta [66], potentially setting up feed-forward loops executed via CKB that are necessary for metastatic potential.

Cytotoxic chemotherapies are frontline treatments for stage IV TNBC. We observed that pairing $\mathrm{cCr}$ with either paclitaxel or doxorubicin enhanced $\mathrm{cCr}$ efficacy. The most potent inhibition of cell growth occurred when $\mathrm{cCr}$ was paired with paclitaxel. cCr treatment was also synergistic with DOX near the $\mathrm{IC}_{50}$ of DOX in two TNBC cell lines (MDAMB-468 and MDA-MB-453), but was antagonistic to cCr in BT549 cells. Interestingly, doxorubicin can impact heart microtubule structure by impairing reassembly [67]. Down- 
regulation of CKB in Skov3 ovarian cancer cells was shown to enhance sensitivity to doxorubicin [20]. However, the exact mechanisms of DOX synergy with cCr remain undefined. We conclude that $\mathrm{cCr}$ therapy inhibits growth and impairs chemotaxis/cell motility through both its effects on cellular metabolism and microtubule dynamics.

There is increasing evidence from a variety of solid cancers that CK inhibition is a promising clinical intervention for patients with metastatic disease. In addition, $\mathrm{cCr}$ likely crosses the blood-brain barrier, and phosphorylated $\mathrm{cCr}$ functions as a phosphagen in the brain $[68,69]$, suggesting that creatine analogs may effectively target brain metastases. Systemic cCr therapy is well tolerated in rodents [70] and in limited clinical trials [15]. In addition, the deletion of $\mathrm{Ckb}$ or systemic administration of $\mathrm{cCr}$ is protective against bone loss in mice [71], suggesting additional potential clinical applications to prevent the osteolytic destruction of bone, the most common site of metastasis in breast cancer patients. A new generation derivative of $\mathrm{cCr}$ with enhanced bioavailability, known as LUM-001, was developed to treat creatine transporter deficiency. LUM-001 was tested in rodents to treat neurodevelopmental cognitive disorders, including autism [68]. More recently, a novel, oral small molecule creatine mimetic, RGX-202 (Inspirna), was shown to inhibit creatine import, to induce apoptosis and to inhibit metastasis to the liver in a variety of pre-clinical colorectal cancer models [72]. Data from early clinical trials (ClinicalTrials.gov: NCT03597581) suggest a favorable safety profile from dosages given twice a day, and confirmed in humans that RGX-202-01, the compound optimized for clinical trials, increases serum and urine levels of creatine in patients with gastrointestinal cancer [72]. Moreover, the anti-tumor activity of RGX-202 is directly correlated with CKB expression levels, as we have observed in metastatic breast cancer models.

\section{Conclusions}

In summary, our results demonstrate that CKB is a major effector of the HIF-1-mediated promotion of metastatic phenotypes in ER-negative breast cancer in vitro and in vivo. CKB is capable of driving aggressive phenotypes in the context of normoxia or hypoxia, likely through its combined roles in managing cellular metabolism, cell cycle progression and microtubule dynamics. A growing body of evidence indicates that $\mathrm{c} C \mathrm{r}$ has anti-tumor efficacy in multiple breast cancer subtypes, including HER2+ breast cancers, and as reported here, in ER-negative/basal breast cancer models. New clinical trials to explore creatine kinase inhibitor monotherapy versus combination with either Taxol or doxorubicin are predicted to demonstrate prolonged survival through the reduced survival of cancer cells in circulation, during colonization and by impairing the growth of cells already disseminated to distant organs, including lung, brain and bone metastases.

Supplementary Materials: The following are available online at https:/ /www.mdpi.com/article/ 10.3390/cancers14010027/s1, Figure S1: Chromatin immunoprecipitation (ChIP) analysis of the Ckb/CKB proximal promoter in PyMT and MCF-7 breast cancer cells; Figure S2: Comparing gene knockdown efficiency of $C k b$ shRNA constructs in PyMT cells; Figure S3: CytoTox Green assays to measure cell viability after exposure to $15 \mathrm{mM}$ or $25 \mathrm{mM} \mathrm{cCr}$; Figure S4: Comparison of CKB levels in additional human breast cancer cell lines; Figure S5: Tubulin networks detected by alpha-tubulin immunostaining following paclitaxel (Taxol) treatment in combination with cCr; Figure S6: Immunostaining of invadopodia coverslips at experimental endpoint; Table S1: Differentially expressed gene list, HIF-1 WT, normoxia vs. HIF-1 WT, hypoxia; Table S2: Differentially expressed gene list, HIF-1 WT, normoxia vs. HIF-1 KO, normoxia; Table S3: Differentially expressed gene list, HIF-1 WT, hypoxia vs. HIF-1 KO, hypoxia; Table S4: Primers and Roche Universal Probe Library (UPL) FAM-labeled probes utilized in real-time PCR assays; Table S5: Primary antibody source and dilution factors utilized in Western blotting, immunofluorescence (IF) staining of cultured cells and DAB-based immunohistochemistry (IHC) staining of tumor tissues; Table S6: Primers used in chromatin immunoprecipitation (ChIP) assays in murine PyMT tumor cells and in human MCF-7 cells; Table S7: Ckb shRNA targeting sequences obtained from The RNAi Consortium (TRC) library purchased through Open Biosystems. 
Author Contributions: R.I.K.: Methodology development, investigation and writing-review and editing. H.P.: Methodology development, investigation and writing-review and editing. The first two authors contributed equally and are listed in alphabetical order. D.L.B.: Conceptualization, methodology development, investigation and writing-review and editing. L.P.S.: Methodology development, investigation and writing-review and editing. D.N.P.: Methodology development and investigation. D.O.: Investigation. D.R.L.: Investigation. M.F. and D.L.J.: Investigation and resources related to data analysis and bioinformatics support. J.Y.: Generation of research materials and methodology. H.S.: Methodology and investigation. T.N.S.: Conceptualization, supervision, funding acquisition, investigation, writing-original draft preparation and writing-review and editing. All authors have read and agreed to the published version of the manuscript.

Funding: This work was supported by NIH/NCI grant R01 CA138488 (to T.N. Seagroves), the Department of Defense Breast Cancer Research Program (BC150640 to T.N. Seagroves), the METAvivor foundation (to T.N. Seagroves), and an internal investigator bridge funding program from the UTHSC Office of Research. D. Layman was supported by a summer fellowship from the West Cancer Center (Memphis, TN, USA) and D. Oluwalana, a graduate student in the UTHSC College of Graduate Health Sciences, was supported through the Department of Pathology. The contents of the article are solely the responsibility of the authors and do not necessarily represent the official views of the $\mathrm{NIH} / \mathrm{NCI}$ or the DoD.

Institutional Review Board Statement: Patient consent was waived since all studies were considered to be Not Human Subjects Research by the UTHSC Institutional Review Board (IRB); study ID, 0705002NHSR. All animal studies were consistent with U.S. Public Health Service policies and the Guide for the Care and Use of Laboratory Animals. Animal protocols were approved by the local UTHSC Institutional Animal Care and Use Committee (Study investigator: T. Seagroves).

Data Availability Statement: Microarray data are publicly available through the Gene Expression Omnibus (GSE\#183694, released 10 September 2021).

Acknowledgments: We are grateful to the staff of the institutional core facilities at The University of Tennessee Health Science Center who supported this work, including William Taylor and Lorne Rose of the Molecular Resource Center (MRC). Deidre Daria assisted with cell cycle analysis at the Flow Cytometry and Cell Sorting (FCCS) Core, and Daniel Johnson provided optimized data analysis workflows and long-term data storage at the Molecular Bioinformatics (mBIO) core. All paraffin-embedded tissue sections were prepared by the Research Histology Core (RHC) with support from LaShawn Barnett. We thank the Department of Pathology and the Cancer Center at UTHSC for support to digitally scan all immunostained slides and for providing access to the 3D Histech software analysis workstation and the Cancer Center for support of the IncuCyte S3 live-imaging system. The UTHSC Department of Pediatrics supports the Seahorse XF instrument managed by Heather Smallwood. We thank Athena Starland-Davenport and Rob Williams for providing access to the Nikon ECLIPSE Ti2 microscope.

Conflicts of Interest: The authors declare no conflict of interest.

\section{References}

1. National Cancer Institute Surveillance, Epidemiology, and End Results (SEER) Program. Cancer Stat Facts: Female Breast Cancer. Available online: https:/ / seer.cancer.gov/statfacts/html/breast.html (accessed on 16 August 2021).

2. Bailey, K.M.; Wojtkowiak, J.W.; Hashim, A.I.; Gillies, R.J. Targeting the metabolic microenvironment of tumors. Adv. Pharmacol. 2012, 65, 63-107. [CrossRef]

3. Zhao, Y.; Butler, E.B.; Tan, M. Targeting cellular metabolism to improve cancer therapeutics. Cell Death Dis. 2013,4 , e532. [CrossRef]

4. Dang, N.H.; Singla, A.K.; Mackay, E.M.; Jirik, F.R.; Weljie, A.M. Targeted Cancer Therapeutics: Biosynthetic and Energetic Pathways Characterized by Metabolomics and the Interplay with Key Cancer Regulatory Factors. Curr. Pharm. Des. 2013, 20, 2637-2647. [CrossRef] [PubMed]

5. Semenza, G.L. HIF-1 mediates metabolic responses to intratumoral hypoxia and oncogenic mutations. J. Clin. Investig. 2013, 123, 3664-3671. [CrossRef]

6. Chiche, J.; Brahimi-Horn, M.C.; Pouyssegur, J. Tumour hypoxia induces a metabolic shift causing acidosis: A common feature in cancer. J. Cell. Mol. Med. 2010, 14, 771-794. [CrossRef] [PubMed]

7. Rohwer, N.; Cramer, T. Hypoxia-mediated drug resistance: Novel insights on the functional interaction of HIFs and cell death pathways. Drug Resist. Update 2011, 14, 191-201. [CrossRef] 
8. Brown, J.M. Exploiting the hypoxic cancer cell: Mechanisms and therapeutic strategies. Mol. Med. Today 2000, 6, 157-162. [CrossRef]

9. Schwab, L.P.; Peacock, D.L.; Majumdar, D.; Ingels, J.F.; Jensen, L.C.; Smith, K.D.; Cushing, R.C.; Seagroves, T.N. Hypoxia-inducible factor 1alpha promotes primary tumor growth and tumor-initiating cell activity in breast cancer. Breast Cancer Res. 2012, 14, R6. [CrossRef]

10. Xia, Y.; Choi, H.K.; Lee, K. Recent advances in hypoxia-inducible factor (HIF)-1 inhibitors. Eur. J. Med. Chem. 2012, 49, 24-40. [CrossRef] [PubMed]

11. Doedens, A.; Johnson, R.S. Transgenic models to understand hypoxia-inducible factor function. Methods EnzyMol. 2007, 435, 87-105. [CrossRef]

12. Keith, B.; Johnson, R.S.; Simon, M.C. HIF1alpha and HIF2alpha: Sibling rivalry in hypoxic tumour growth and progression. Nat. Rev. Cancer 2012, 12, 9-22. [CrossRef] [PubMed]

13. Wallimann, T.; Wyss, M.; Brdiczka, D.; Nicolay, K.; Eppenberger, H.M. Intracellular compartmentation, structure and function of creatine kinase isoenzymes in tissues with high and fluctuating energy demands: The 'phosphocreatine circuit' for cellular energy homeostasis. Biochem. J. 1992, 281 Pt 1, 21-40. [CrossRef] [PubMed]

14. Wallimann, T.; Tokarska-Schlattner, M.; Schlattner, U. The creatine kinase system and pleiotropic effects of creatine. Amino Acids 2011, 40, 1271-1296. [CrossRef] [PubMed]

15. Wyss, M.; Kaddurah-Daouk, R. Creatine and creatinine metabolism. Physiol. Rev. 2000, 80, 1107-1213. [CrossRef]

16. Glover, L.E.; Bowers, B.E.; Saeedi, B.; Ehrentraut, S.F.; Campbell, E.L.; Bayless, A.J.; Dobrinskikh, E.; Kendrick, A.A.; Kelly, C.J.; Burgess, A.; et al. Control of creatine metabolism by HIF is an endogenous mechanism of barrier regulation in colitis. Proc. Natl. Acad. Sci. USA 2013, 110, 19820-19825. [CrossRef]

17. Streijger, F.; Oerlemans, F.; Ellenbroek, B.A.; Jost, C.R.; Wieringa, B.; Van der Zee, C.E. Structural and behavioural consequences of double deficiency for creatine kinases BCK and UbCKmit. Behav. Brain Res. 2005, 157, 219-234. [CrossRef] [PubMed]

18. Mooney, S.M.; Rajagopalan, K.; Williams, B.H.; Zeng, Y.; Christudass, C.S.; Li, Y.; Yin, B.; Kulkarni, P.; Getzenberg, R.H. Creatine kinase brain overexpression protects colorectal cells from various metabolic and non-metabolic stresses. J. Cell Biochem. 2011, 112, 1066-1075. [CrossRef]

19. Zarghami, N.; Giai, M.; Yu, H.; Roagna, R.; Ponzone, R.; Katsaros, D.; Sismondi, P.; Diamandis, E.P. Creatine kinase BB isoenzyme levels in tumour cytosols and survival of breast cancer patients. Br. J. Cancer 1996, 73, 386-390. [CrossRef] [PubMed]

20. Li, X.H.; Chen, X.J.; Ou, W.B.; Zhang, Q.; Lv, Z.R.; Zhan, Y.; Ma, L.; Huang, T.; Yan, Y.B.; Zhou, H.M. Knockdown of creatine kinase B inhibits ovarian cancer progression by decreasing glycolysis. Int. J. Biochem. Cell Biol. 2013, 45, 979-986. [CrossRef]

21. Chen, H.; Pimienta, G.; Gu, Y.; Sun, X.; Hu, J.; Kim, M.S.; Chaerkady, R.; Gucek, M.; Cole, R.N.; Sukumar, S.; et al. Proteomic characterization of Her2/neu-overexpressing breast cancer cells. Proteomics 2010, 10, 3800-3810. [CrossRef]

22. Chen, W.Z.; Pang, B.; Yang, B.; Zhou, J.G.; Sun, Y.H. Differential proteome analysis of conditioned medium of BPH-1 and LNCaP cells. Chin. Med. J. (Engl.) 2011, 124, 3806-3809.

23. Xu, Y.; Cao, L.Q.; Jin, L.Y.; Chen, Z.C.; Zeng, G.Q.; Tang, C.E.; Li, G.Q.; Duan, C.J.; Peng, F.; Xiao, Z.Q.; et al. Quantitative proteomic study of human lung squamous carcinoma and normal bronchial epithelial acquired by laser capture microdissection. J. BioMed Biotechnol. 2012, 2012, 510418. [CrossRef] [PubMed]

24. Zeng, G.Q.; Zhang, P.F.; Deng, X.; Yu, F.L.; Li, C.; Xu, Y.; Yi, H.; Li, M.Y.; Hu, R.; Zuo, J.H.; et al. Identification of candidate biomarkers for early detection of human lung squamous cell cancer by quantitative proteomics. Mol. Cell Proteomics 2012, 11, M111.013946. [CrossRef] [PubMed]

25. Teicher, B.A.; Menon, K.; Northey, D.; Liu, J.; Kufe, D.W.; Kaddurah-Daouk, R. Cyclocreatine in cancer chemotherapy. Cancer Chemother. Pharmacol. 1995, 35, 411-416. [CrossRef]

26. Mulvaney, P.T.; Stracke, M.L.; Nam, S.W.; Woodhouse, E.; O’Keefe, M.; Clair, T.; Liotta, L.A.; Khaddurah-Daouk, R.; Schiffmann, E. Cyclocreatine inhibits stimulated motility in tumor cells possessing creatine kinase. Int. J. Cancer 1998, 78, 46-52. [CrossRef]

27. Loo, J.M.; Scherl, A.; Nguyen, A.; Man, F.Y.; Weinberg, E.; Zeng, Z.; Saltz, L.; Paty, P.B.; Tavazoie, S.F. Extracellular metabolic energetics can promote cancer progression. Cell 2015, 160, 393-406. [CrossRef]

28. Papalazarou, V.; Zhang, T.; Paul, N.R.; Juin, A.; Cantini, M.; Maddocks, O.D.K.; Salmeron-Sanchez, M.; Machesky, L.M. The creatine-phosphagen system is mechanoresponsive in pancreatic adenocarcinoma and fuels invasion and metastasis. Nat. Metab. 2020, 2, 62-80. [CrossRef]

29. Kuiper, J.W.; van Horssen, R.; Oerlemans, F.; Peters, W.; van Dommelen, M.M.; te Lindert, M.M.; ten Hagen, T.L.; Janssen, E.; Fransen, J.A.; Wieringa, B. Local ATP generation by brain-type creatine kinase (CK-B) facilitates cell motility. PLoS ONE 2009, 4, e5030. [CrossRef] [PubMed]

30. van Horssen, R.; Janssen, E.; Peters, W.; van de Pasch, L.; Lindert, M.M.; van Dommelen, M.M.; Linssen, P.C.; Hagen, T.L.; Fransen, J.A.; Wieringa, B. Modulation of cell motility by spatial repositioning of enzymatic ATP/ADP exchange capacity. J. Biol. Chem. 2009, 284, 1620-1627. [CrossRef]

31. Dent, R.; Hanna, W.M.; Trudeau, M.; Rawlinson, E.; Sun, P.; Narod, S.A. Pattern of metastatic spread in triple-negative breast cancer. Breast Cancer Res. Treat 2009, 115, 423-428. [CrossRef]

32. Network, C.G.A. Comprehensive molecular portraits of human breast tumours. Nature 2012, 490, 61-70. [CrossRef]

33. Nagy, A.; Lanczky, A.; Menyhart, O.; Gyorffy, B. Validation of miRNA prognostic power in hepatocellular carcinoma using expression data of independent datasets. Sci. Rep. 2018, 8, 9227. [CrossRef] 
34. Brooks, D.L.; Schwab, L.P.; Krutilina, R.; Parke, D.N.; Sethuraman, A.; Hoogewijs, D.; Schorg, A.; Gotwald, L.; Fan, M.; Wenger, R.H.; et al. ITGA6 is directly regulated by hypoxia-inducible factors and enriches for cancer stem cell activity and invasion in metastatic breast cancer models. Mol. Cancer 2016, 15, 26. [CrossRef] [PubMed]

35. Oosthuyse, B.; Moons, L.; Storkebaum, E.; Beck, H.; Nuyens, D.; Brusselmans, K.; Van Dorpe, J.; Hellings, P.; Gorselink, M.; Heymans, S.; et al. Deletion of the hypoxia-response element in the vascular endothelial growth factor promoter causes motor neuron degeneration. Nat. Genet. 2001, 28, 131-138. [CrossRef] [PubMed]

36. Choi, B.H.; Ha, Y.; Ahn, C.H.; Huang, X.; Kim, J.M.; Park, S.R.; Park, H.; Park, H.C.; Kim, S.W.; Lee, M. A hypoxia-inducible gene expression system using erythropoietin $3^{\prime}$ untranslated region for the gene therapy of rat spinal cord injury. Neurosci. Lett. 2007, 412, 118-122. [CrossRef] [PubMed]

37. Brooks, D.L.; Seagroves, T.N. Chromatin Immunoprecipitation of HIF-alpha in Breast Tumor Cells Using Wild Type and Loss of Function Models. Methods Mol. Biol. 2018, 1742, 67-79. [CrossRef]

38. Martin, K.H.; Hayes, K.E.; Walk, E.L.; Ammer, A.G.; Markwell, S.M.; Weed, S.A. Quantitative measurement of invadopodiamediated extracellular matrix proteolysis in single and multicellular contexts. J. Vis. Exp. 2012, 66, e4119. [CrossRef]

39. Tallarida, R.J. An overview of drug combination analysis with isobolograms. J. Pharmacol. Exp. Ther. 2006, 319, 1-7. [CrossRef]

40. Bergnes, G.; Yuan, W.; Khandekar, V.S.; O’Keefe, M.M.; Martin, K.J.; Teicher, B.A.; Kaddurah-Daouk, R. Creatine and phosphocreatine analogs: Anticancer activity and enzymatic analysis. Oncol. Res. 1996, 8, 121-130.

41. Hunter, K.W.; Broman, K.W.; Voyer, T.L.; Lukes, L.; Cozma, D.; Debies, M.T.; Rouse, J.; Welch, D.R. Predisposition to efficient mammary tumor metastatic progression is linked to the breast cancer metastasis suppressor gene Brms1. Cancer Res. 2001, 61, 8866-8872.

42. Wang, F.; Samudio, I.; Safe, S. Transcriptional activation of rat creatine kinase B by 17beta-estradiol in MCF-7 cells involves an estrogen responsive element and GC-rich sites. J. Cell Biochem. 2001, 84, 156-172. [CrossRef]

43. Stiehl, D.P.; Bordoli, M.R.; Abreu-Rodriguez, I.; Wollenick, K.; Schraml, P.; Gradin, K.; Poellinger, L.; Kristiansen, G.; Wenger, R.H. Non-canonical HIF-2alpha function drives autonomous breast cancer cell growth via an AREG-EGFR/ErbB4 autocrine loop. Oncogene 2012, 31, 2283-2297. [CrossRef] [PubMed]

44. Balasubramani, M.; Day, B.W.; Schoen, R.E.; Getzenberg, R.H. Altered expression and localization of creatine kinase B, heterogeneous nuclear ribonucleoprotein $\mathrm{F}$, and high mobility group box 1 protein in the nuclear matrix associated with colon cancer. Cancer Res. 2006, 66, 763-769. [CrossRef] [PubMed]

45. Lillie, J.W.; O’Keefe, M.; Valinski, H.; Hamlin, H.A., Jr.; Varban, M.L.; Kaddurah-Daouk, R. Cyclocreatine (1-carboxymethyl2-iminoimidazolidine) inhibits growth of a broad spectrum of cancer cells derived from solid tumors. Cancer Res. 1993, 53, 3172-3178.

46. Martin, K.; Winslow, E.; Okeefe, M.; Khandekar, V.; Hamlin, A.; Lillie, J.; Kaddurahdaouk, R. Specific targeting of tumor cells by the creatine analog cyclocreatine. Int. J. Oncol. 1996, 9, 993-999. [CrossRef] [PubMed]

47. Martin, K.J.; Winslow, E.R.; Kaddurah-Daouk, R. Cell cycle studies of cyclocreatine, a new anticancer agent. Cancer Res. 1994, 54, 5160-5165.

48. Hoosein, N.M.; Martin, K.J.; Abdul, M.; Logothetis, C.J.; Kaddurah-Daouk, R. Antiproliferative effects of cyclocreatine on human prostatic carcinoma cells. Anticancer Res. 1995, 15, 1339-1342.

49. Miller, E.E.; Evans, A.E.; Cohn, M. Inhibition of rate of tumor growth by creatine and cyclocreatine. Proc. Natl. Acad. Sci. USA 1993, 90, 3304-3308. [CrossRef]

50. Fenouille, N.; Bassil, C.F.; Ben-Sahra, I.; Benajiba, L.; Alexe, G.; Ramos, A.; Pikman, Y.; Conway, A.S.; Burgess, M.R.; Li, Q.; et al. The creatine kinase pathway is a metabolic vulnerability in EVI1-positive acute myeloid leukemia. Nat. Med. 2017, 23, 301-313. [CrossRef] [PubMed]

51. Kurmi, K.; Hitosugi, S.; Yu, J.; Boakye-Agyeman, F.; Wiese, E.K.; Larson, T.R.; Dai, Q.; Machida, Y.J.; Lou, Z.; Wang, L.; et al. Tyrosine Phosphorylation of Mitochondrial Creatine Kinase 1 Enhances a Druggable Tumor Energy Shuttle Pathway. Cell Metab. 2018, 28, 833-847.e838. [CrossRef]

52. Vranic, S.; Gatalica, Z.; Wang, Z.Y. Update on the molecular profile of the MDA-MB-453 cell line as a model for apocrine breast carcinoma studies. Oncol. Lett. 2011, 2, 1131-1137. [CrossRef] [PubMed]

53. Chevalier, C.; Cannet, A.; Descamps, S.; Sirvent, A.; Simon, V.; Roche, S.; Benistant, C. ABL tyrosine kinase inhibition variable effects on the invasive properties of different triple negative breast cancer cell lines. PLoS ONE 2015, 10, e0118854. [CrossRef]

54. Martin, K.J.; Vassallo, C.D.; Teicher, B.A.; Kaddurah-Daouk, R. Microtubule stabilization and potentiation of taxol activity by the creatine analog cyclocreatine. Anticancer Drugs 1995, 6, 419-426. [CrossRef]

55. de Heer, E.C.; Jalving, M.; Harris, A.L. HIFs, angiogenesis, and metabolism: Elusive enemies in breast cancer. J. Clin. Investig. 2020, 130, 5074-5087. [CrossRef] [PubMed]

56. Gatza, M.L.; Kung, H.N.; Blackwell, K.L.; Dewhirst, M.W.; Marks, J.R.; Chi, J.T. Analysis of tumor environmental response and oncogenic pathway activation identifies distinct basal and luminal features in HER2-related breast tumor subtypes. Breast Cancer Res. 2011, 13, R62. [CrossRef] [PubMed]

57. Lee, J.W.; Bae, S.H.; Jeong, J.W.; Kim, S.H.; Kim, K.W. Hypoxia-inducible factor (HIF-1)alpha: Its protein stability and biological functions. Exp. Mol. Med. 2004, 36, 1-12. [CrossRef] [PubMed]

58. Semenza, G.L. Targeting HIF-1 for cancer therapy. Nat. Rev. Cancer 2003, 3, 721-732. [CrossRef] 
59. Decking, U.K.; Alves, C.; Wallimann, T.; Wyss, M.; Schrader, J. Functional aspects of creatine kinase isoenzymes in endothelial cells. Am. J. Physiol. Cell Physiol. 2001, 281, C320-C328. [CrossRef]

60. Loike, J.D.; Kozler, V.F.; Silverstein, S.C. Creatine kinase expression and creatine phosphate accumulation are developmentally regulated during differentiation of mouse and human monocytes. J. Exp. Med. 1984, 159, 746-757. [CrossRef]

61. Rahbani, J.F.; Roesler, A.; Hussain, M.F.; Samborska, B.; Dykstra, C.B.; Tsai, L.; Jedrychowski, M.P.; Vergnes, L.; Reue, K.; Spiegelman, B.M.; et al. Creatine kinase B controls futile creatine cycling in thermogenic fat. Nature 2021, 590, 480-485. [CrossRef]

62. Attanasio, F.; Caldieri, G.; Giacchetti, G.; van Horssen, R.; Wieringa, B.; Buccione, R. Novel invadopodia components revealed by differential proteomic analysis. Eur. J. Cell Biol. 2011, 90, 115-127. [CrossRef]

63. Zhang, L.; Zhu, Z.; Yan, H.; Wang, W.; Wu, Z.; Zhang, F.; Zhang, Q.; Shi, G.; Du, J.; Cai, H.; et al. Creatine promotes cancer metastasis through activation of Smad2/3. Cell Metab. 2021, 33, 1111-1123.e1114. [CrossRef]

64. Chen, Q.; Zhang, N.; Gray, R.S.; Li, H.; Ewald, A.J.; Zahnow, C.A.; Pan, D. A temporal requirement for Hippo signaling in mammary gland differentiation, growth, and tumorigenesis. Genes Dev. 2014, 28, 432-437. [CrossRef]

65. Jing, X.; Yang, X.; Zhang, W.; Wang, S.; Cui, X.; Du, T.; Li, T. Mechanical loading induces HIF-1alpha expression in chondrocytes via YAP. Biotechnol. Lett. 2020, 42, 1645-1654. [CrossRef]

66. Jia, Y.; Li, H.Y.; Wang, J.; Wang, Y.; Zhang, P.; Ma, N.; Mo, S.J. Phosphorylation of 14-3-3zeta links YAP transcriptional activation to hypoxic glycolysis for tumorigenesis. Oncogenesis 2019, 8, 31. [CrossRef] [PubMed]

67. Rabkin, S.W.; Sunga, P. The effect of doxorubicin (adriamycin) on cytoplasmic microtubule system in cardiac cells. J. Mol. Cell Cardiol. 1987, 19, 1073-1083. [CrossRef]

68. Cacciante, F.; Gennaro, M.; Sagona, G.; Mazziotti, R.; Lupori, L.; Cerri, E.; Putignano, E.; Butt, M.; Do, M.T.; McKew, J.C.; et al. Cyclocreatine treatment ameliorates the cognitive, autistic and epileptic phenotype in a mouse model of Creatine Transporter Deficiency. Sci. Rep. 2020, 10, 18361. [CrossRef]

69. Uemura, T.; Ito, S.; Masuda, T.; Shimbo, H.; Goto, T.; Osaka, H.; Wada, T.; Couraud, P.O.; Ohtsuki, S. Cyclocreatine Transport by SLC6A8, the Creatine Transporter, in HEK293 Cells, a Human Blood-Brain Barrier Model Cell, and CCDSs Patient-Derived Fibroblasts. Pharm. Res. 2020, 37, 61. [CrossRef]

70. Kurosawa, Y.; Degrauw, T.J.; Lindquist, D.M.; Blanco, V.M.; Pyne-Geithman, G.J.; Daikoku, T.; Chambers, J.B.; Benoit, S.C.; Clark, J.F. Cyclocreatine treatment improves cognition in mice with creatine transporter deficiency. J. Clin. Investig. 2012, 122, $2837-2846$. [CrossRef] [PubMed]

71. Chang, E.J.; Ha, J.; Oerlemans, F.; Lee, Y.J.; Lee, S.W.; Ryu, J.; Kim, H.J.; Lee, Y.; Kim, H.M.; Choi, J.Y.; et al. Brain-type creatine kinase has a crucial role in osteoclast-mediated bone resorption. Nat. Med. 2008, 14, 966-972. [CrossRef]

72. Kurth, I.; Yamaguchi, N.; Andreu-Agullo, C.; Tian, H.S.; Sridhar, S.; Takeda, S.; Gonsalves, F.C.; Loo, J.M.; Barlas, A.; ManovaTodorova, K.; et al. Therapeutic targeting of SLC6A8 creatine transporter suppresses colon cancer progression and modulates human creatine levels. Sci. Adv. 2021, 7, eabi7511. [CrossRef] [PubMed] 